جدل المفارقة بين الفلسفة والعلم

د. دعاء صسني صستز أبوهبل

مدرس منتلب الابد

كلية الآداب جامعة الؤو أدي الجديد 
07. 
هنـاك فكرة شـائعة عند البعض بـأن الفلسـفة لا علاقـة لهـا بـالعلم، ولا علاقـة للعلم بالفلسفة، وهذا الموقف الذي يتبناه البعض يقارن بين الفلسفة والعلم، حيث يحقق العلم تقدماً

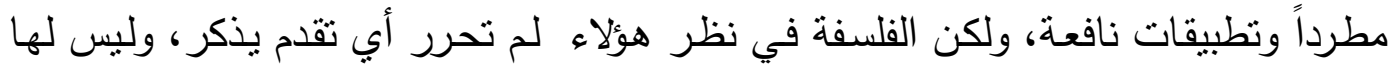

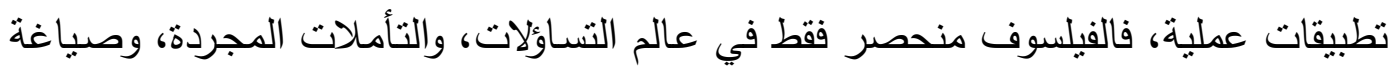

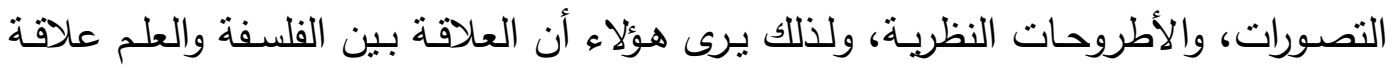
متباعدة.

ولقد درجت التقرقة بين الفلسفة والعلم على أسـاس إختصاص أولاهما بالنظر العقلي

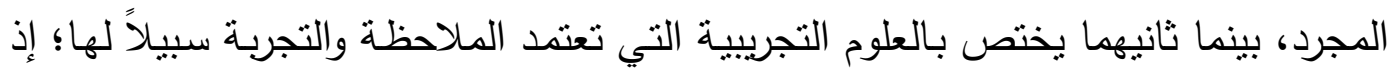

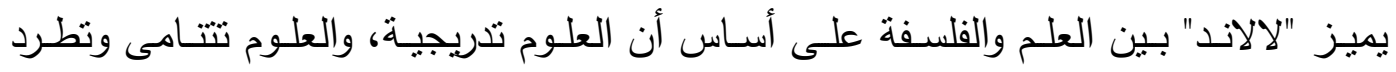
بتوسيع مجالها، أما الفلسفة فهي بخلاف ذلك منغلقة في دائرة مسائل تظل جوهرياً هي نفسها

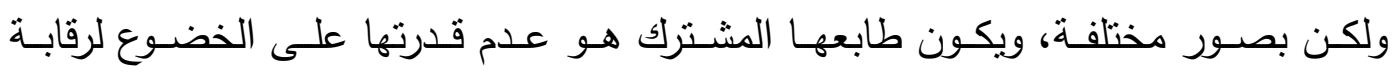

الإختبار (') (1)

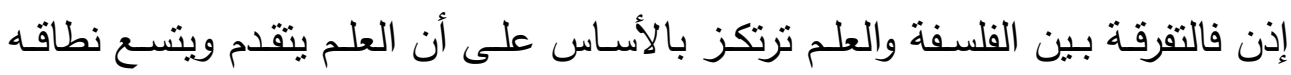

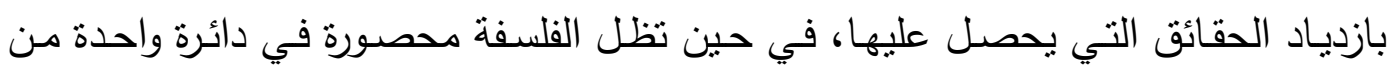
الحقائق، وإن كانت الصور التي تعبر عن هذه الحقائق مختلفة ومتفاوتة (؟). ولكن مجال فلسفة العلوم بمثابـة دليل واضـح على مثانـة وقوة الارتباط بين الفلسفة

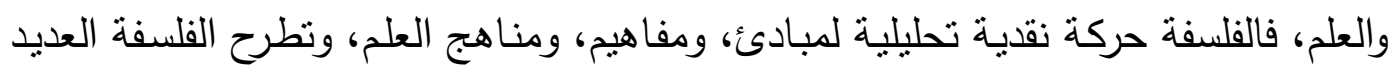

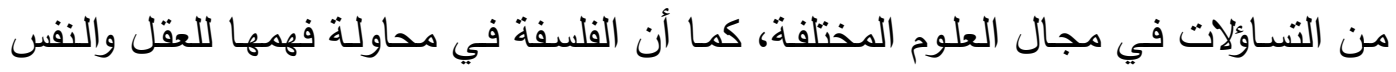
كانت تكثف للعلم عن طبيعة العقل الذي هو أداة من أدواته التي يستعين بها على ضبط المشاهدات والتجارب، والذي أصبح اليوم ضمن دراسة علم النفس ... وغيرها من المجالات. فالعلاقة بين الفلسفة والعلم علاقة تكاملية بالرغم من اختلاف طبيعة كل منهما عن

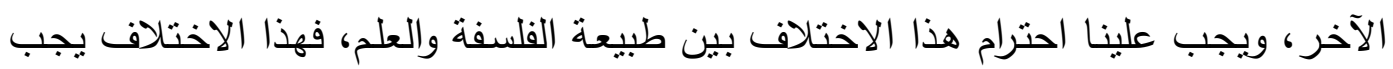
ألا يؤدي إلي تعارض أو صدام، فالفلسفة شمولية تتظر للكون بنظرة شمولية كلية، أمسا العلم فهو روئة متخصصة جزئية، لذا نتـاول الباحثة في هذه الدراسة جدل المفارقة بين الفلسفة

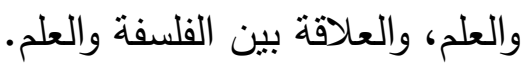

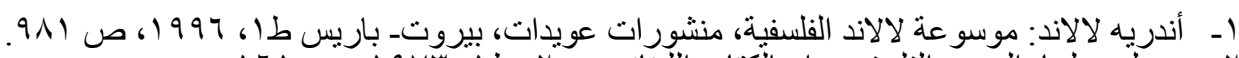

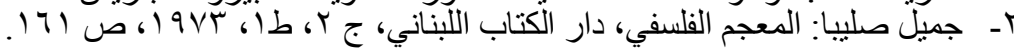




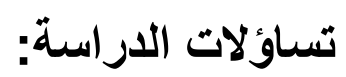

1- ما المقصود بالمفارقة؟

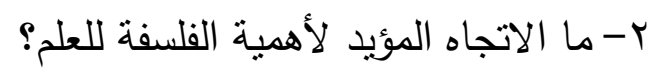

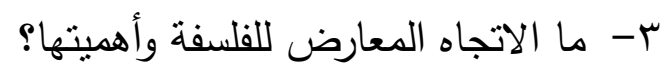

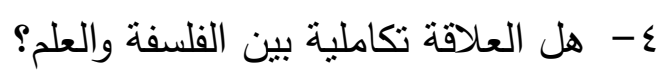
0- ما فلسفة العلوم، وما أهميتها؟ أهداف الدراسة:

- - التعرف على ماهية المفارقة. - التعرف على الاتجاه المؤيد لأهمية الفلسفة للعلم. - التعرف على الموقف المعارض لأهمية الفلسفة للعلم. - التعرف على العلاقة التكاملية بين الفلسفة والعلم. - - أهمية فلسفة العلوم. -

\section{مفهوم الجدل: - ماته}

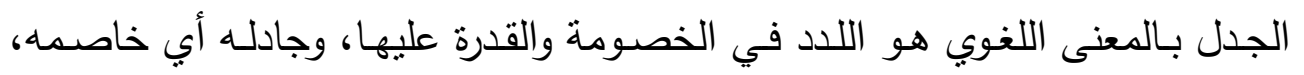

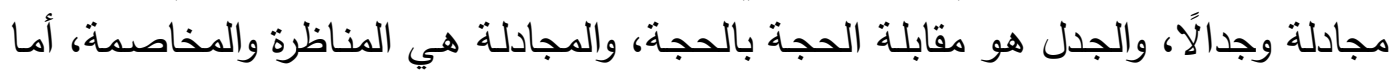

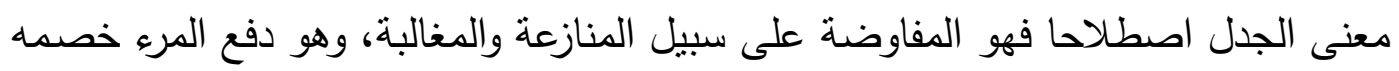
عن إفساد قوله بالحجة.

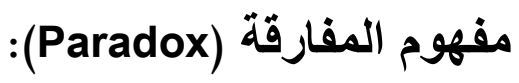

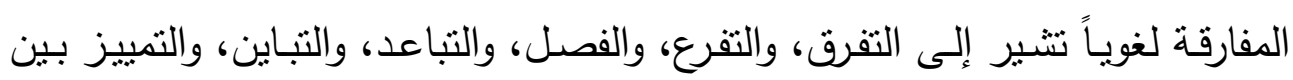

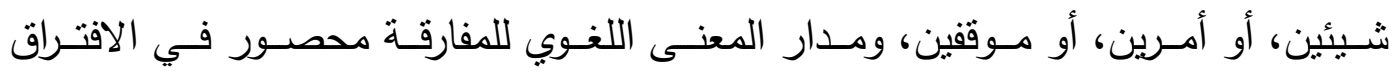
والاختلاف، لذلك هي تكون نقيض ألمبن ألمع والإجتماع.

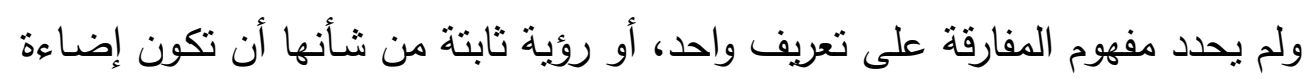

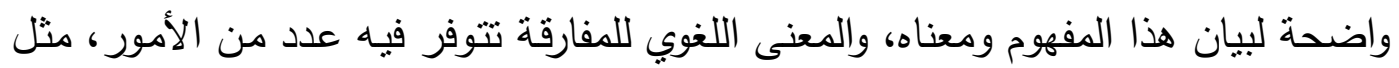

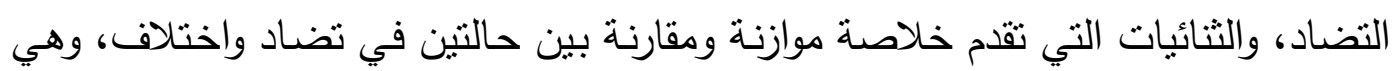
ثنائيات تحمل دلالات وتقع فيها معانٍ كثيرة.

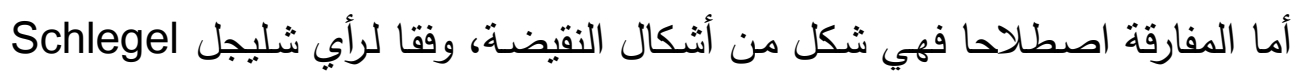

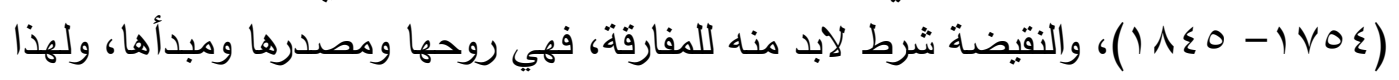


فهي تعني إدراكنا لحقيقة أن العالم في ماهيته متتاقض ظاهريا، والمفارقة برهان منطقي

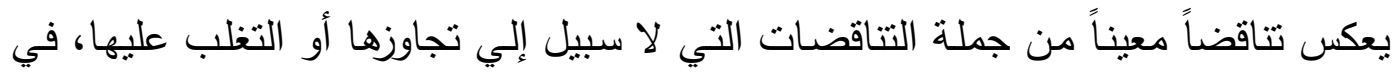

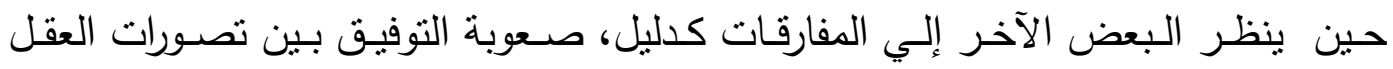
الخالص، ومعطيات العالم العيني" (').

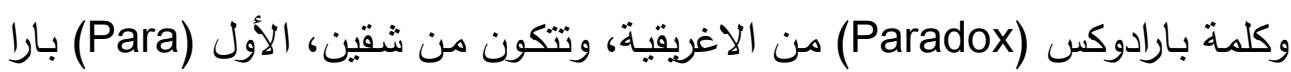

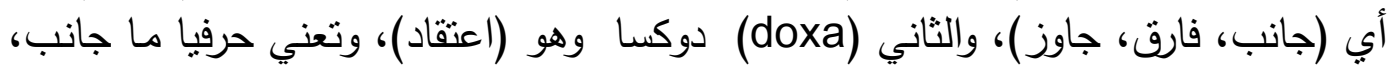

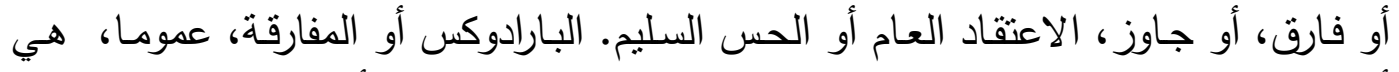

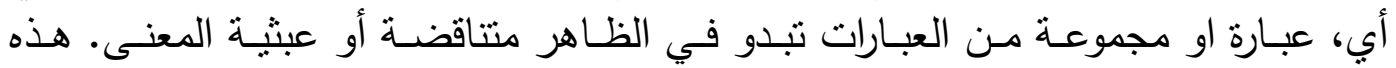

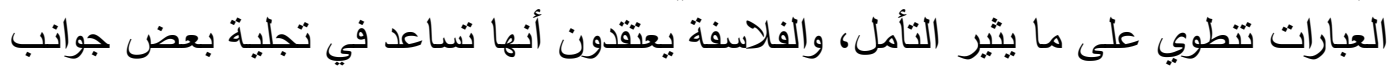

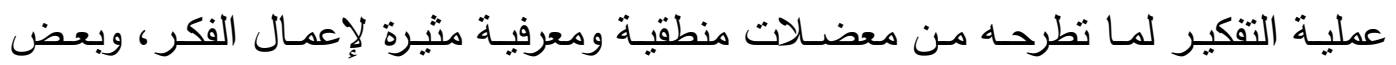

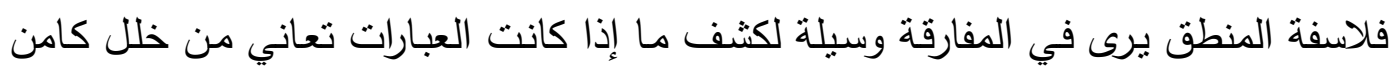
في منطق تعليلها أو فرضياتها.

\section{الاتجاه المؤيد لأهمية القلسفة للعلم:}

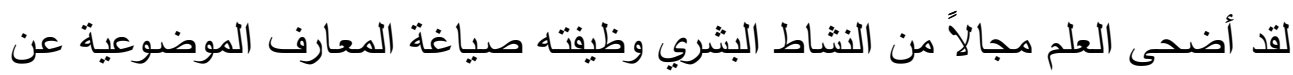

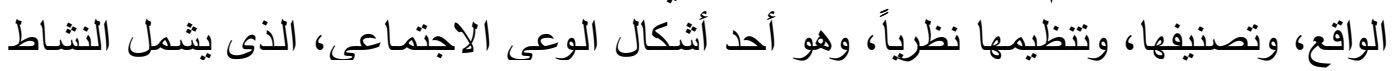

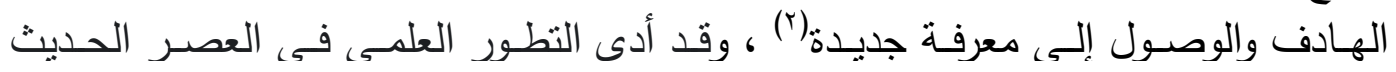

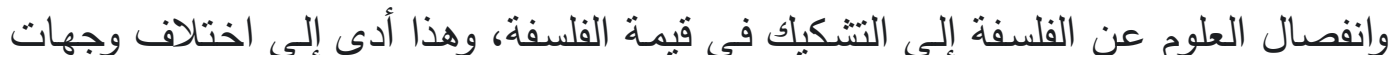

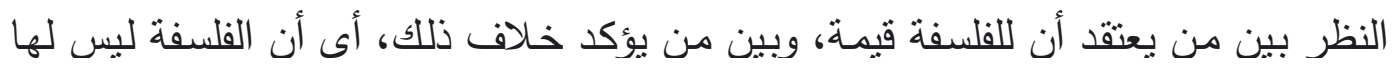

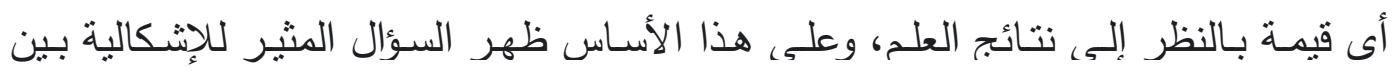

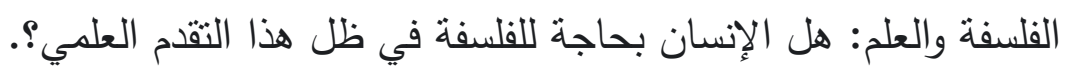

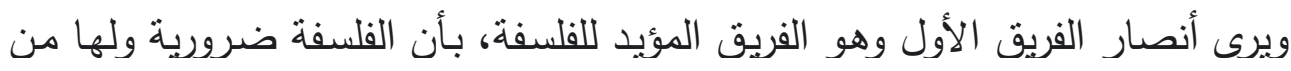

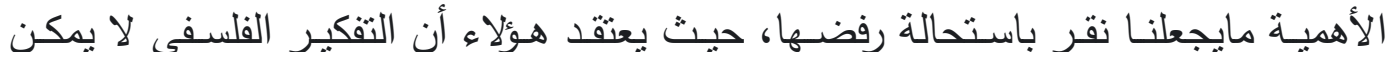

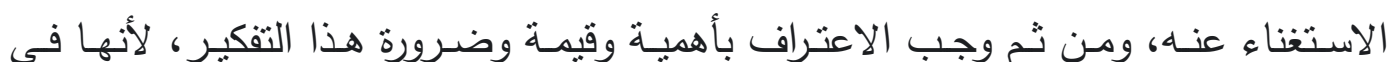

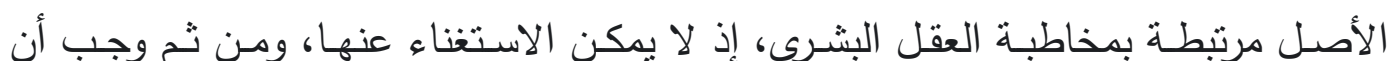

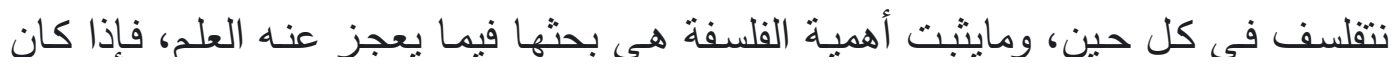

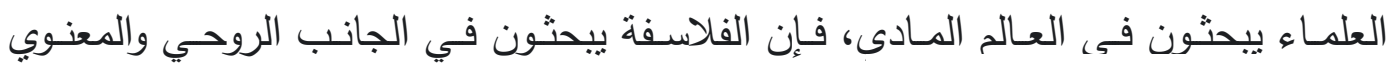
كالبحث في الأخلاق، والقيم...الخ.

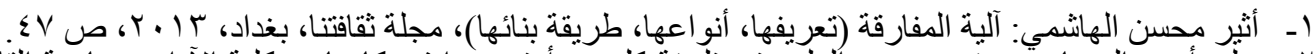

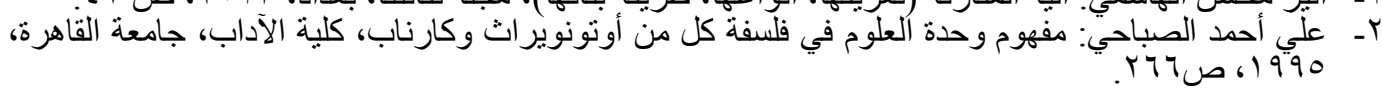


وفى الفكر القديم حينما كانت العلوم أجزاءً من الفلسفة، لم تكن الصلة صلة جزء بكل وحسب، وانما كانت صلة اهتمام من الفلسفة الأولى، بتحليل وتبرير المبادئ والمسلمات التى هلى

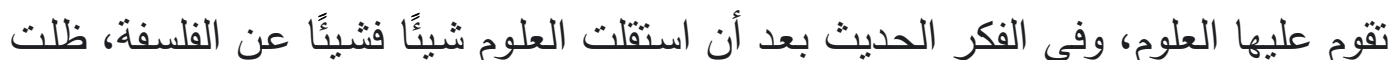

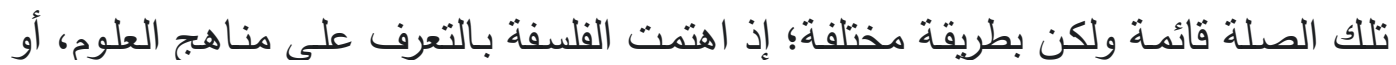
طرق التفكير التى كفلت للعلوم تقدمًا مطردًا، فنشأ فرع فى الفلسفة يهتم بالدراسات المنطقية

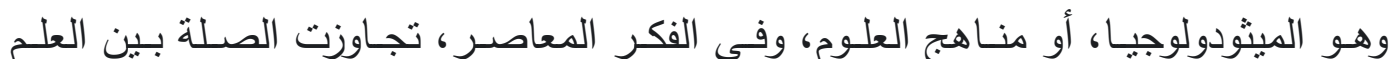

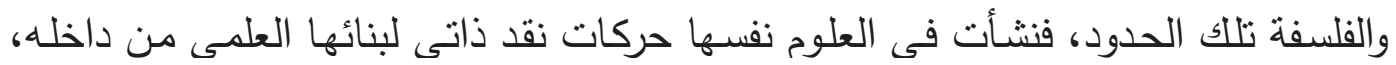
لاختبار الأفكار، والمبادئ، أو الأسس التي يقوم عليها البناء، وبيان الارتباط بينها، وبين

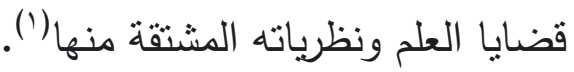

وبالرغم من ذلك يضطر العلم النامى بشكل دائم أن يدخل فى نظرياته مفاهيم ذات

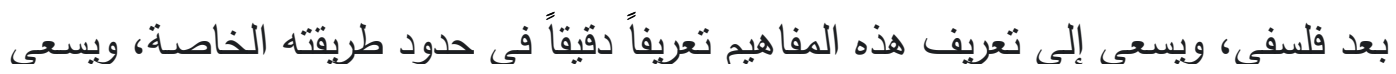

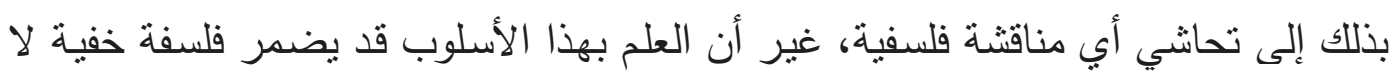
يعترف بها (r).

فالمسائل الفلسفية للعلوم هى قيادة العلم وتوجيهه نقداً وتقويما، بمختلف جوانبه القبلية

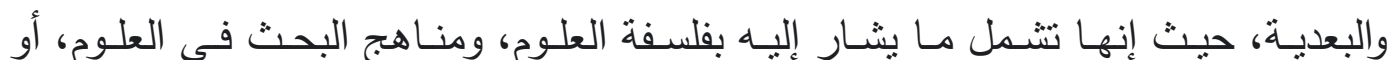

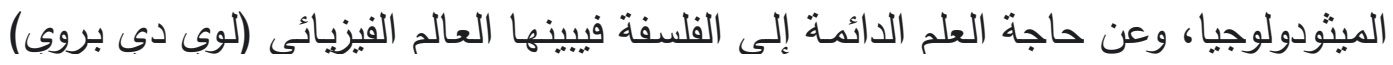
بقوله: "يضطر العلم النامى بشكل دائم أن يدخل فى نظرياته مفاهيم ذات بعد فلسفى مثنل

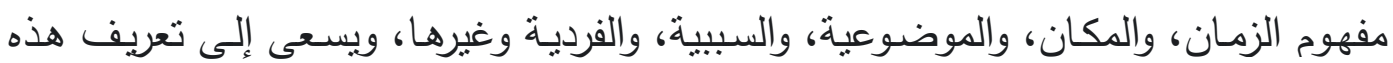

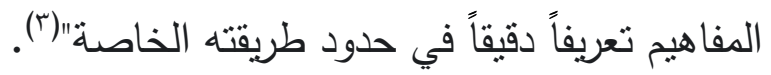

ومما لا شك فيه أن مجرد التفكير فى المبادئ والطرق الخاصـة بعلم من العلوم ليس

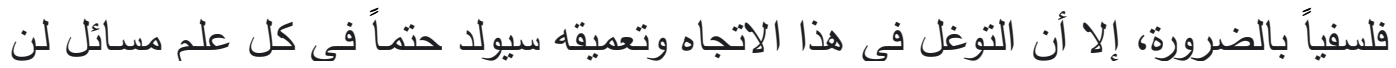

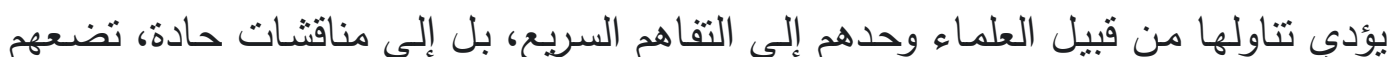

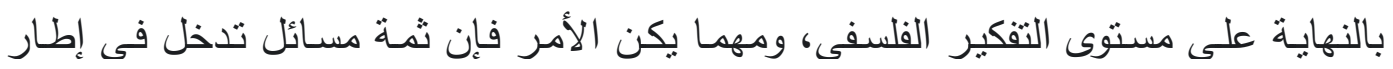
التفكير الفلسفى، وهذا يفسر لنا ظهور خلافات بين العلماء ليس من الممكن فهمها إلا إذا

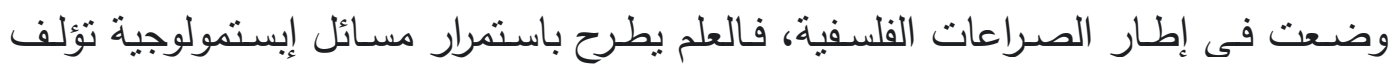
جزءاً من المسائل الفلسفية للعلم (ء).

1- http://www.maaber.org/issue october17/epistemology1.htm.

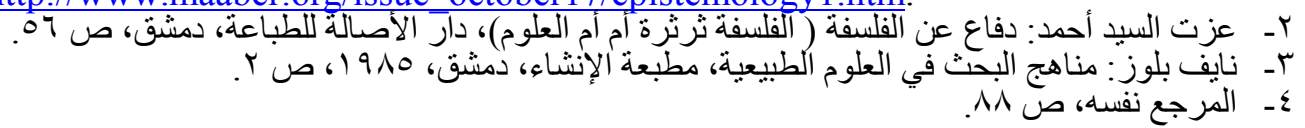


والفيلسوف منذ ولادة العلم الحديث لم يعد يتدخل فى المعرفة العلمية فى حد ذاتها،

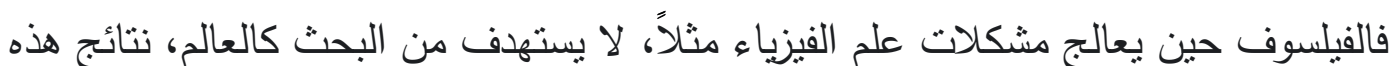

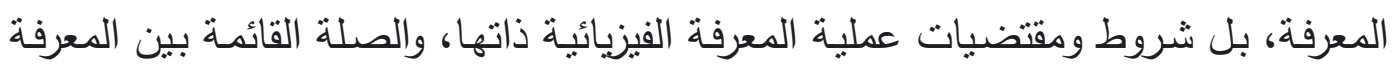
الفيزيائية والواقع، وصلاحية المعاني والمفاهيم المستخدمة في العلم ('). لذلك يقول هيجل :"إن الدفاع عن الفلسفة هو الدفاع عن الإنسان"، وهذا يعنى أن كل

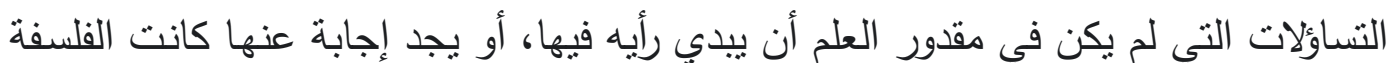
تتصدى لهاهوبتمثل دور الفلسفة الحقيقى فى تغيير العالم وليس تفسيره فحسب، فالأفكار الفلسفية هى بداية لمختلف الثورات التى حدثت فى العالم، ولعل هذا ما دعت إليه الآيات

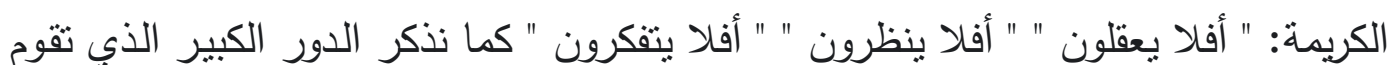

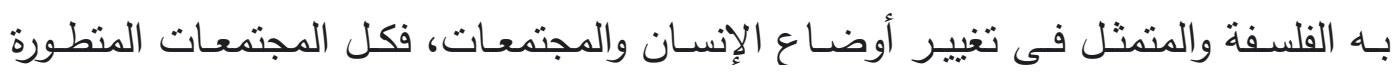
تاريخياً وعلمياً تكون منطلقاتها أفكار فلسفية.

ولم تكن الفلسفة يوماً منفصلة عن العلم، بل إن الثورة العلمية أناحت المجال لدخول القلسفة فى قلب الحقل العلىى من خلال مناقشـة أبعاد الإنجازات العلمية، فالانفجار العلمى بـى

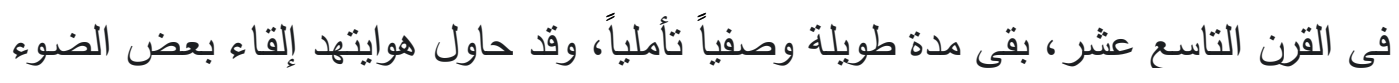

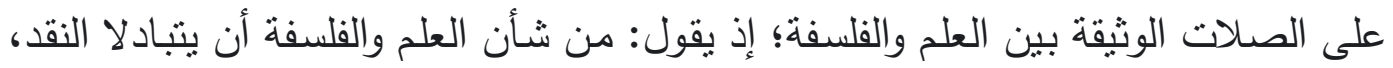

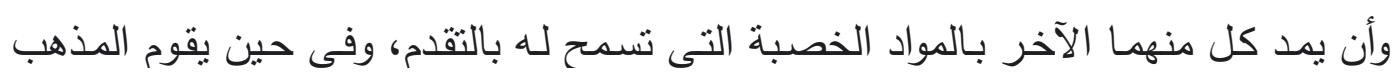

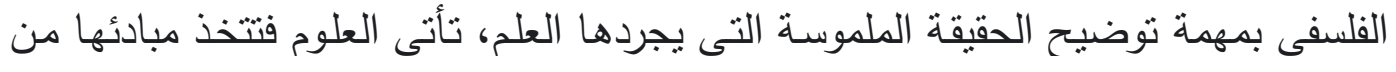
تللك الوقائع الملموسة التى يقدمها المذهب الفلسفى،كما أن إدراك القيمة الحضـارية للنظريات

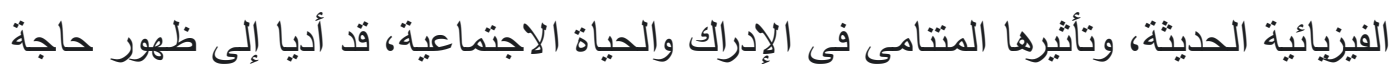

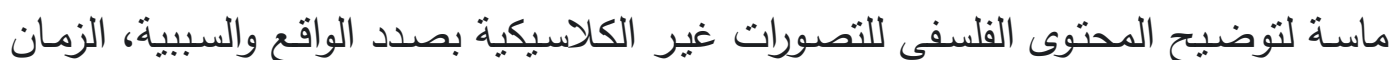

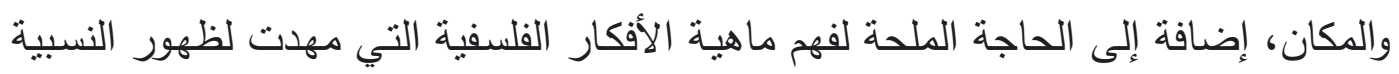

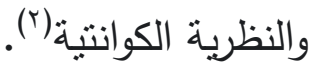
يقول أينشتاين: - 20

يقوم النظام الكامل للفيزياء النظرية على المفاهيم والخلاصـات التى يتم التوصل إليها

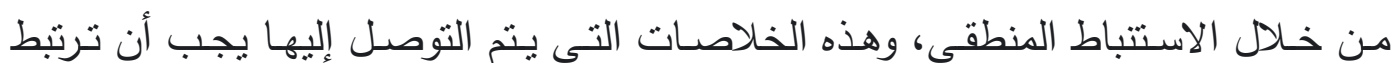

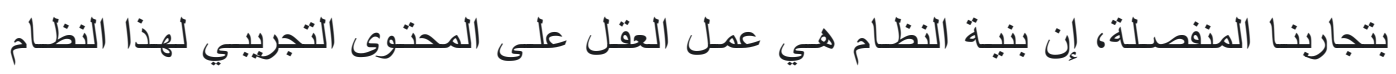

2- http://www.maaber.org/issue october17/epistemology1.htm.

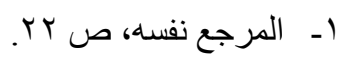


وعلاقاته المتبادلة، وتكمن القيمة العظمى وشرعية كل نظام من إمكانيـة وجود مثل هذا

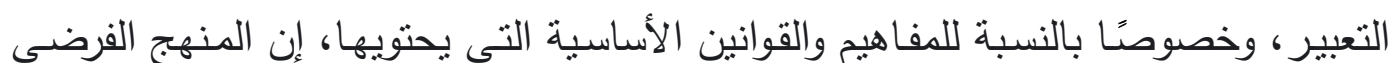

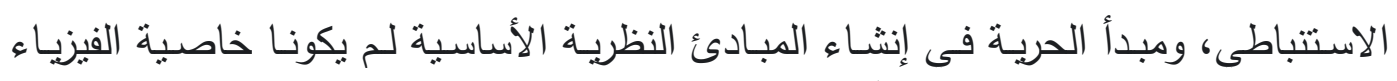

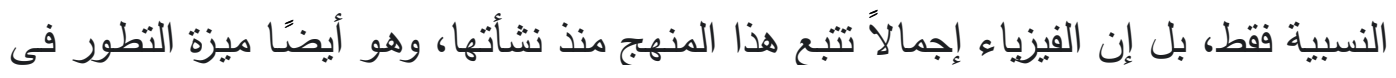

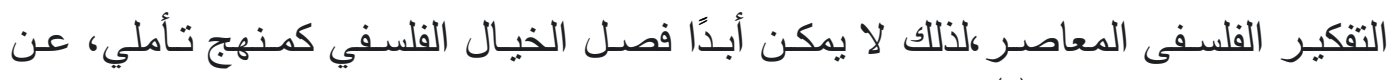

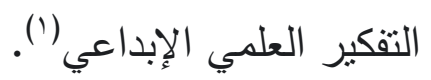

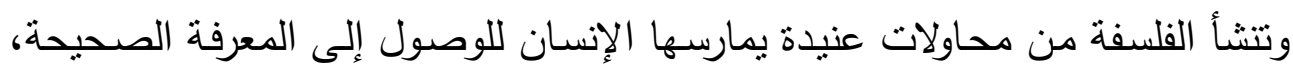

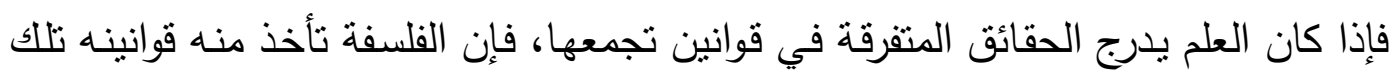

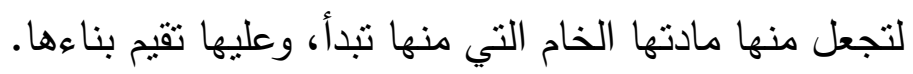

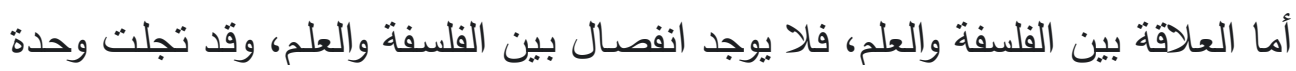

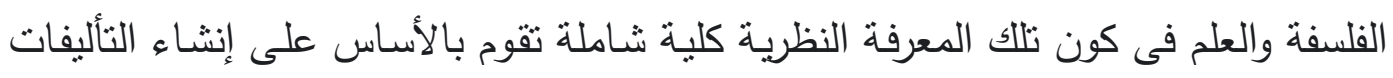

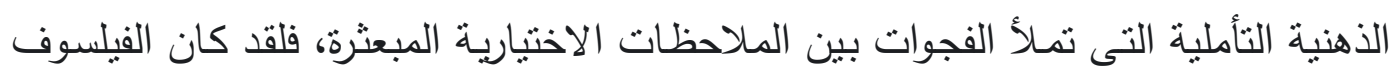

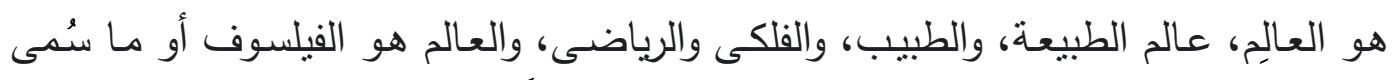

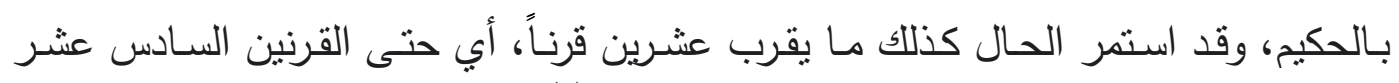

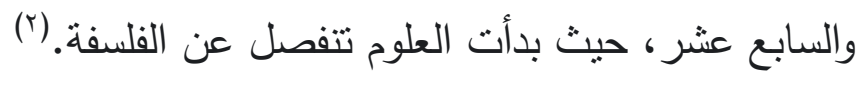

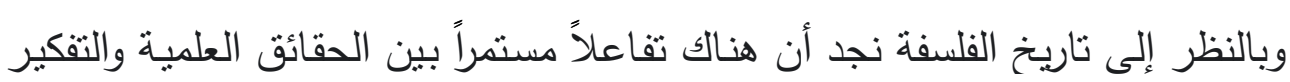

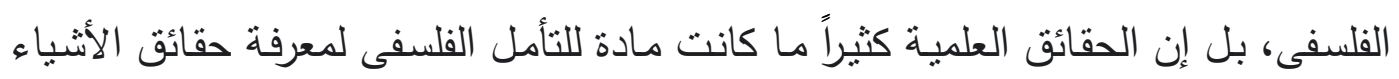

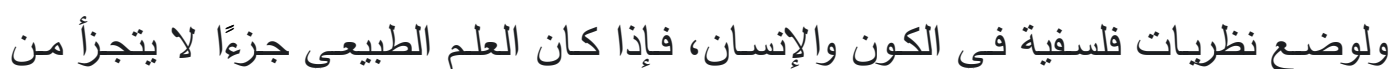

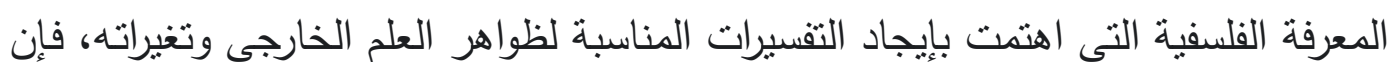

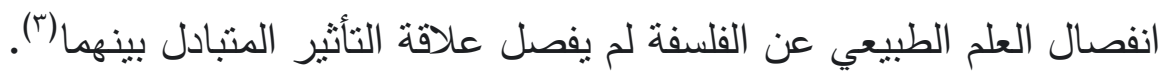

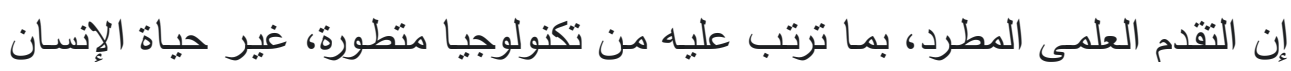

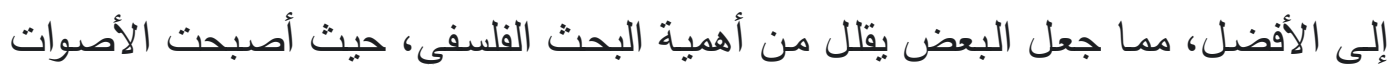

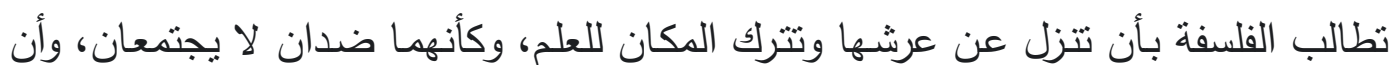

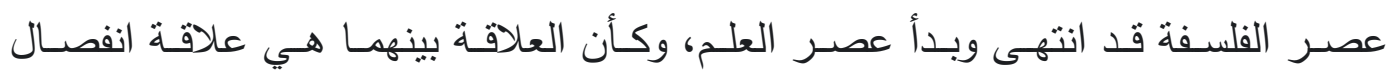
وتعارض(£). (1)

1- http://www.maaber.org/issue october17/epistemology1.htm.

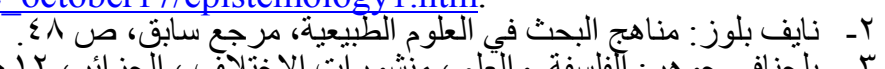

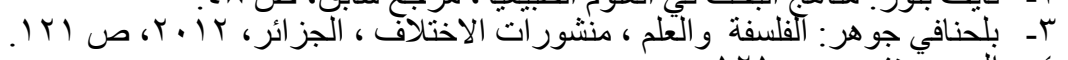

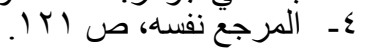


ويؤكد رسل على ضرورة الربط بين الفلسفة والعلم، حيث يقول إن الفلسفة لا تختلف فى

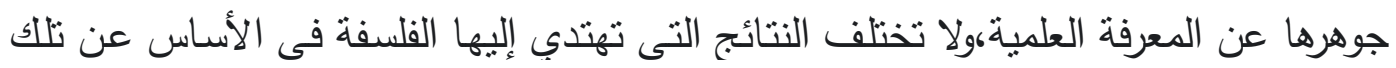

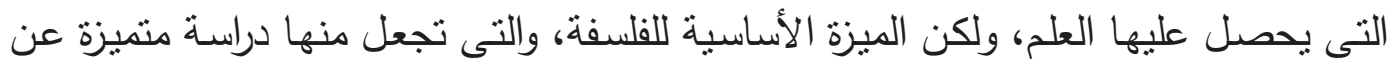
العلم هى النقد، فهى تعرض المبادئ التى يستخدمها العالم، والتى تتجلى فى الحياة اليومية للنقد الفاحص، وتبحث عما قد يكون فيها من تتاقض، ولا تقبلها إلا بعد التمحيص الدقيق ولتئ وبعد

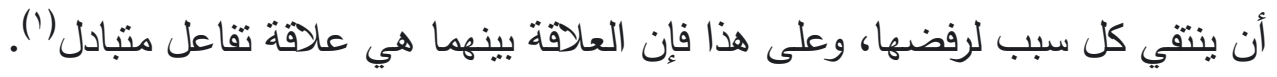

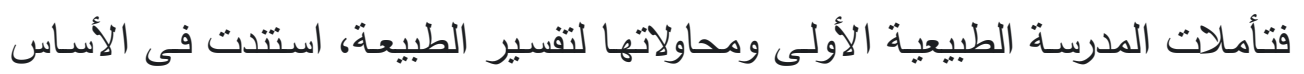

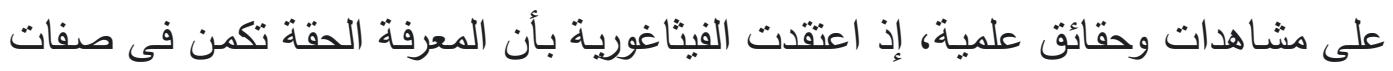

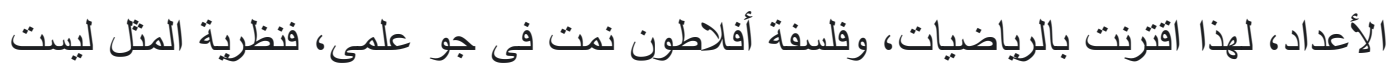

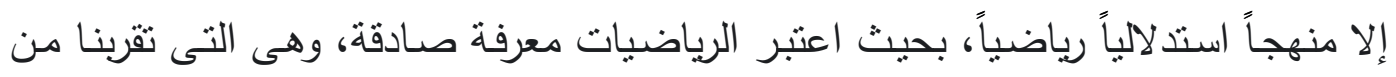

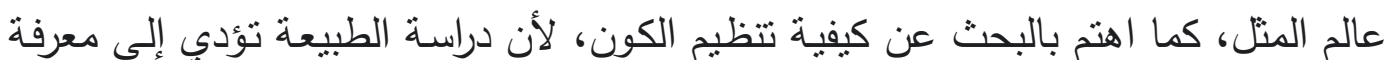

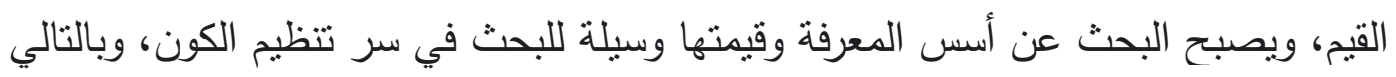

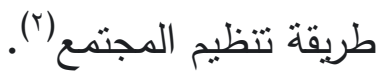

لا يمكن إنكار أهمية الفلسفة، ولكن التقدم العلمى جعل الكثير من العلمـاء يثورون عليها باعتبار أنها مجرد تساؤلات لا تتتهى، وليس لها أي أهمية، فهى تتعلق بالغيبيات، وقد

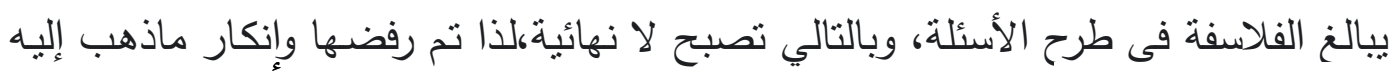

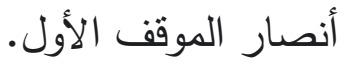

\section{الاتجاة المعارض للقلسفة وأهميتها:}

وعلى الجانب الآخر يـرفض الكثثر من العلمـاء الفلسفة لعدة اعتبـارات من أهمها:

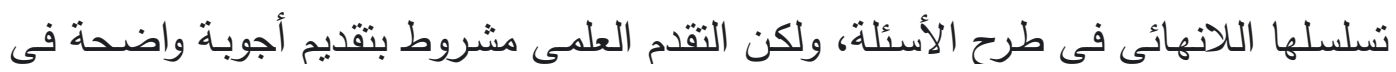

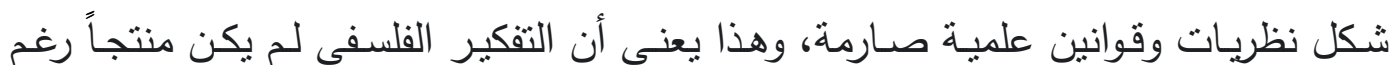
استحواذه على الفكر الإنسانى لقرون عديدة، وبالتالى كانت قيمة الفلسفة مثيرة للشكوك لأنها

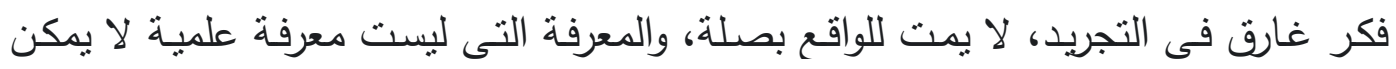

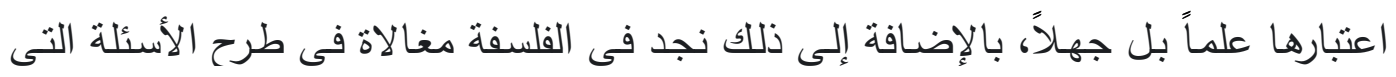
تتعلق بالغيبيات والأمور الإلهية، والحديث عن الفلسفة فى ظل التطورات العلمية يبدو غريباً

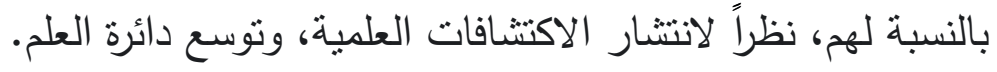


ولذلك تتعرض الفلسفة لعدة تحديات، بل وهجمات، شككت فى قيمتها والجدوى منها،

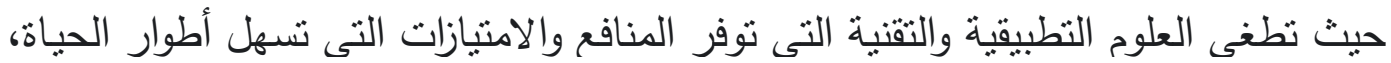

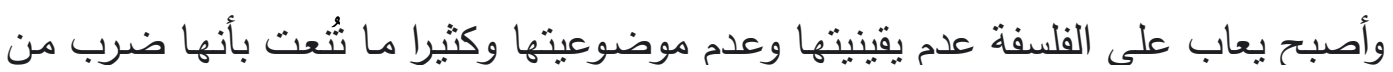

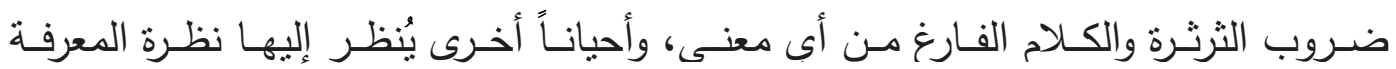

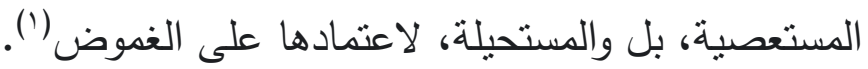
فالفلسفة لاى البعض بعيدة عن الحياة، ولا تهتم بالمشاكل الآنية التى تؤرق الإنسان،

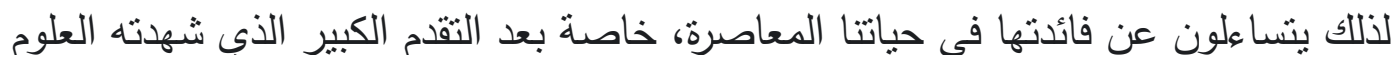
والفنون، ويتساءلون عن الفائدة المنتظرة من الاطلاع على آراء قدماء الفلاسفة في اليونان

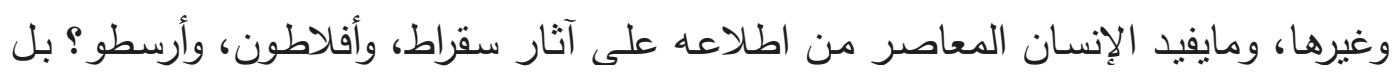

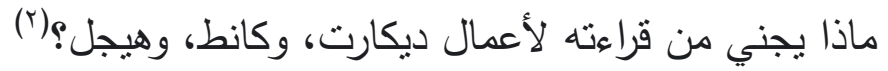

كما يَرْون أن الفلسفة دن المعارف التى يمكن الاستغناء عنها، لأن وسائل الاستقصاء

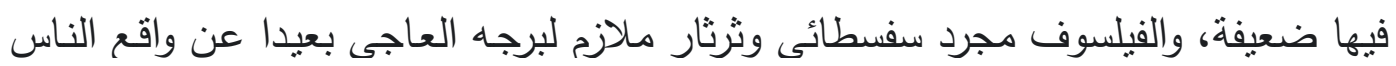

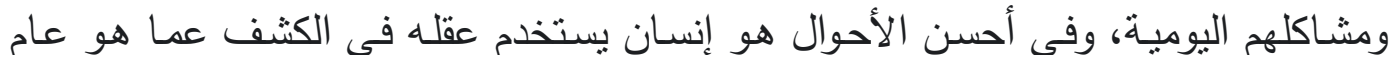

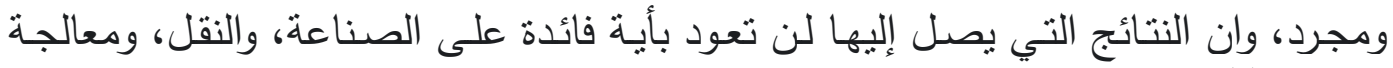

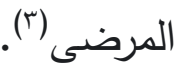

كما أن الفلاسفة أنفسهم أثند الناس اختلافاً فى مواقفه حول المسألة الواحدة؟ بل إنهم لم يتفقوا على تعربف موحد للفلسفة، ومختلفين أيضاً فى مباحثها التى تتباين من فيلسوف إلى في إنى آخر ، وليس لهح منهج واحد، وغياب المنهج الموحد يعنى بالضرورة الاختلاف فى النتائج، لهذا

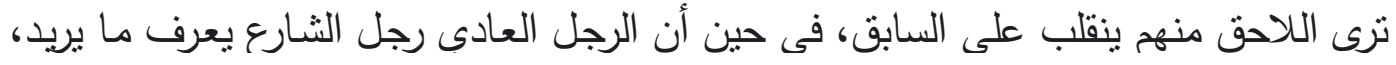

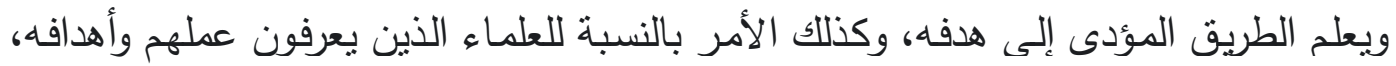

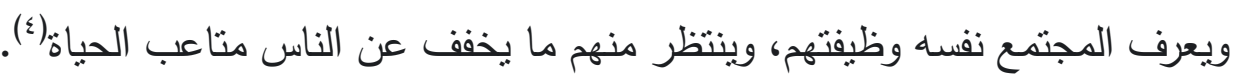
إن الفلسفة على هذا ما هى إلا ترفًا فكريًا لن بمنح الغذاء، والسكن، والصحة لغيره،

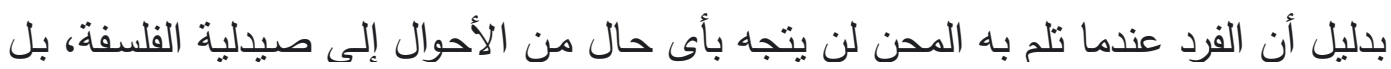

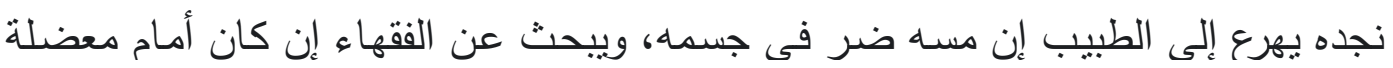

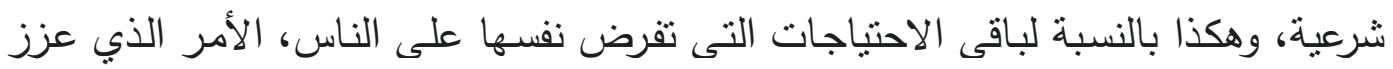
الموقف الذي يحط من قيمة الفلسفه وينفي أن يكون لها دور في المجتمع.

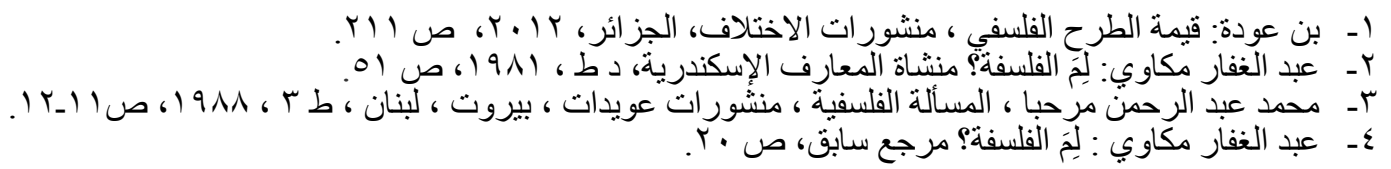


ولكن مهما قال أعداء الفلسفة، ونسبوا إليها من نقائص وعيوب، ومهمـا كاد لها

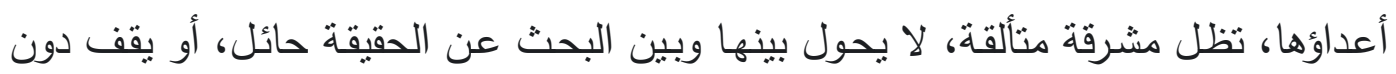

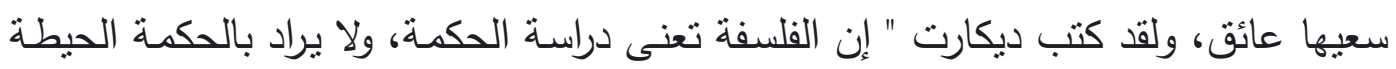

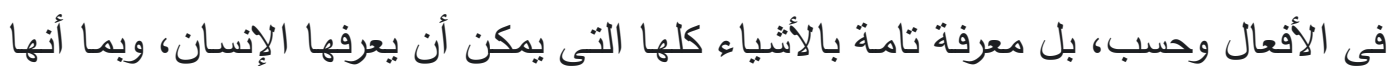

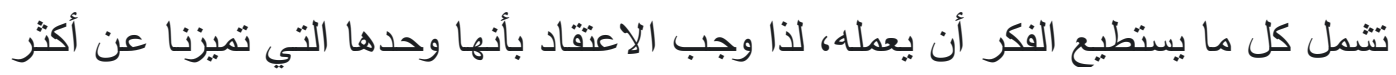
الناس توحشاً وهمجية" (')

\section{العلاقة التكاملية بين القلسفة والعلم:}

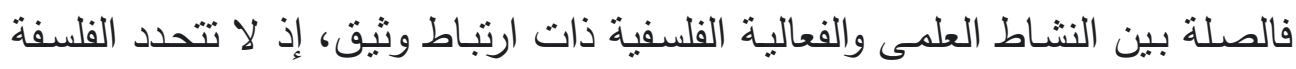

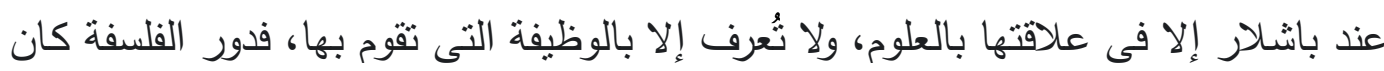

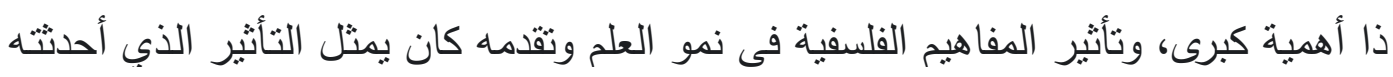

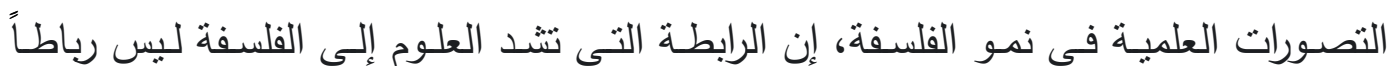

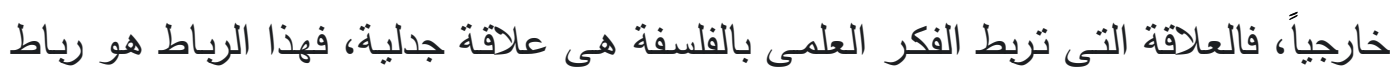

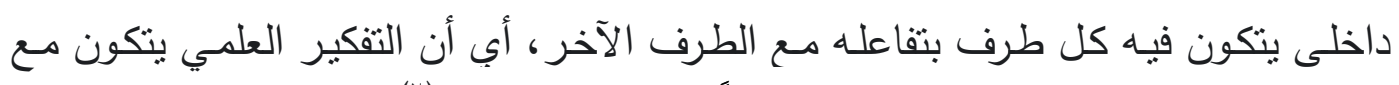
الفلسفة، فتاريخ الفكر العلمي لم يكن منفصلاً عن الفكر الفلسفي (؟).

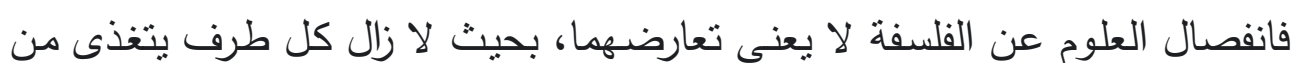

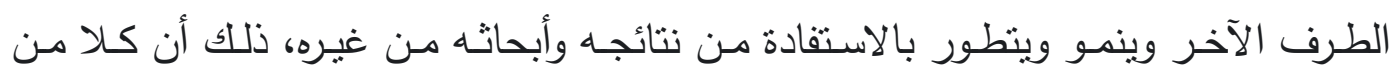

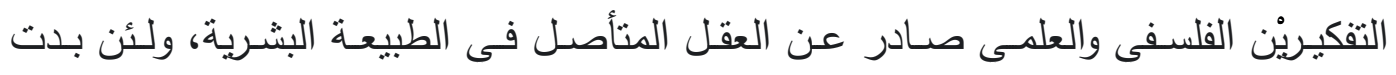

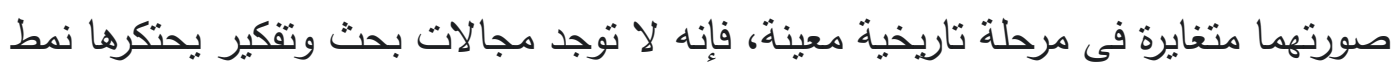

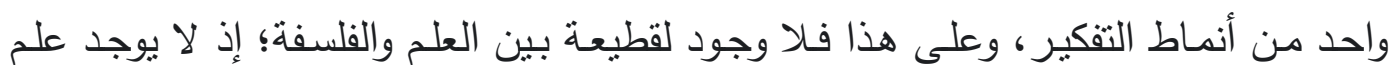

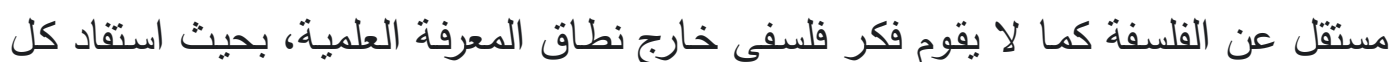

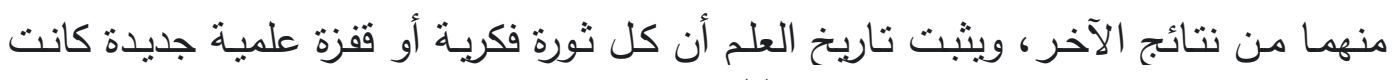

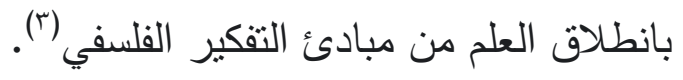

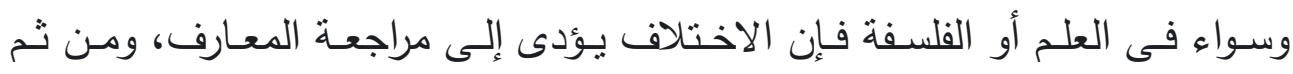

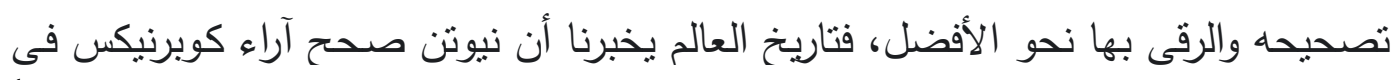
حركة الكواكب، ولم يُنظر إلى هذا على أنه اختلاف سلبي، ثم جاء اينشتين وقدم تصوراً 
جديداً لحركة الكواكب بالاستتاد لفكرة الزمكان، ثم أن التضارب الموجود بين الفلاسفة، نجد ما يقابله لدى العلماء والفقهاء، ومصدر الاختلاف هو طبيعة الذهن البشري نفسهاه(').

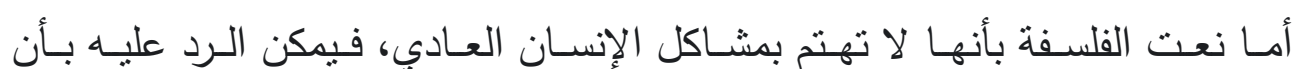

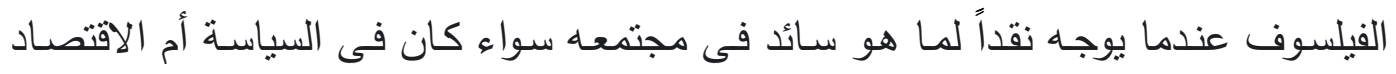

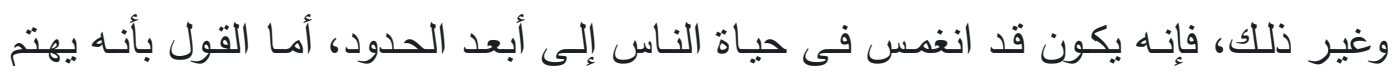
بالمجردات، فهذا لا ينقص من قيمة الفلسفة، لأن البحث لا ينبغى أن يقتصر على المئى الماديات

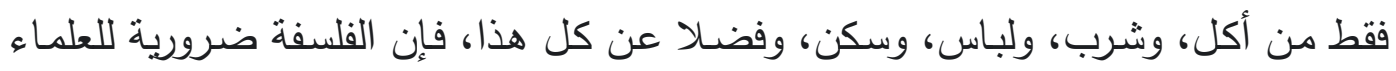

لأنهم يفتقرون دائماً إلى أساس نظري ينطلقون منه، وهو ما تعمل الفلسفة على توفيره(؟). وتبرز أهمية الفلسفة أكثر عندما نتتبع أسباب تقدم الثعوب وعوامل حضارتها، عندها سنجد أن الفلسفة والتفكير العقلى الحر يقف دائما خلف هذه المنجزات، وقد تأكد لفلاسفة

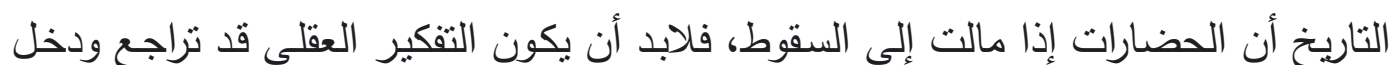

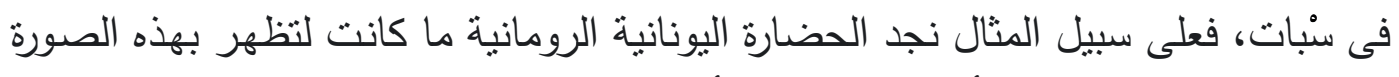

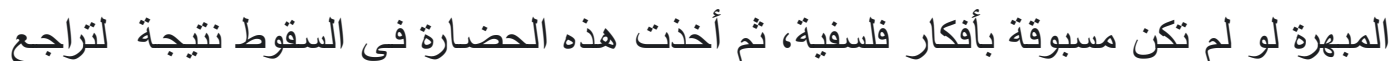

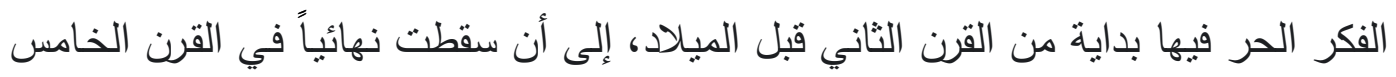
للميلاد (r). (لمكر

لا يمكن إنكار أدلة الطرفين وقبولها إلى حد ما بدليل أن العلاقة بين الفلسفة والعلم هى علاقة تداخل وتكامل، وتلاحم وظيفى، مما يثبت أن التفكير الفلسفى لا يمكن الاستغناء

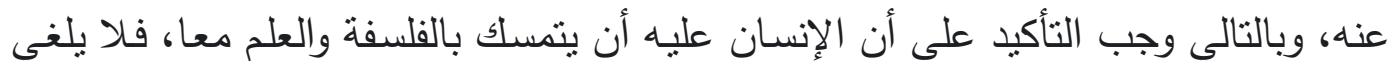

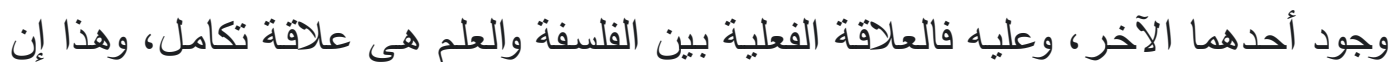

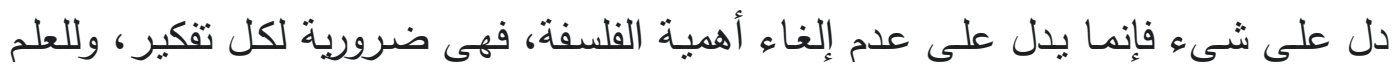

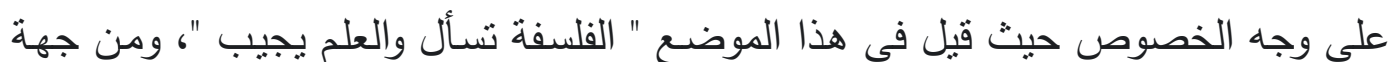
أخرى نجد تطور الفلسفة هو الآخر مقرونًا بمدى تقدم العلوم، ولكي تولد الفلسفة أو تجدد نشأتها لابد لها من وجود العلم. والفلسفة وليدة تدبر العقل البشري فى الوجود، وفى البحث عن الجواهر الكامنة وراء

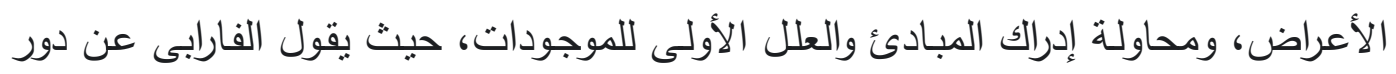
الفلسفة": لا يوجد شيء من موجودات العالم إلا وللفلسفة فيه دخل، فالغاية من الفلسفة هي

1 - http://elearning.univ-annaba.dz/mod/page/view.php?id=3800.

2- http://elearning.univ-annaba.dz/mod/page/view.php?id $=3800$.

3 - Filosofia-nabilmeciad.eklablog.com/-c29532230.

ov. 
تدوين العلوم لمعرفة موجودات العالم، وإيضاح أحوالها على ما هي عليه، وذلك من غير

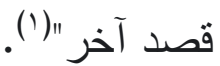

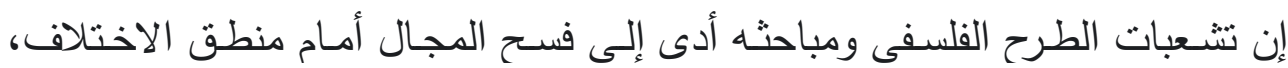

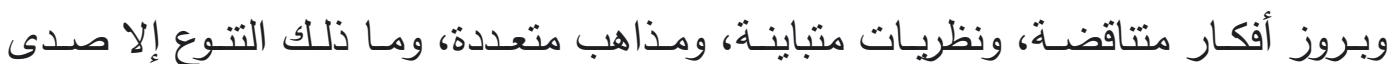

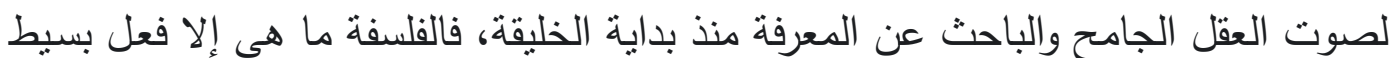

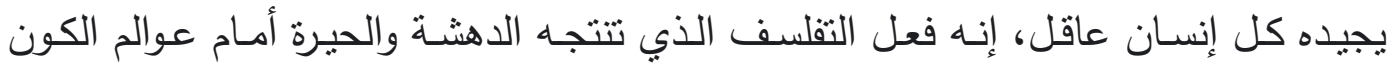
وألغازه)

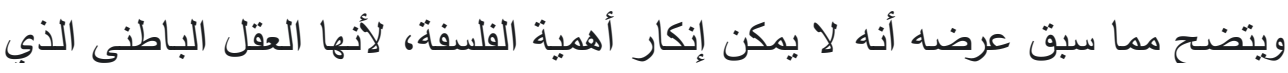

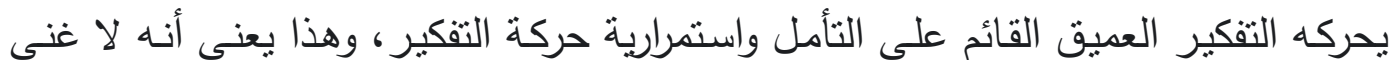

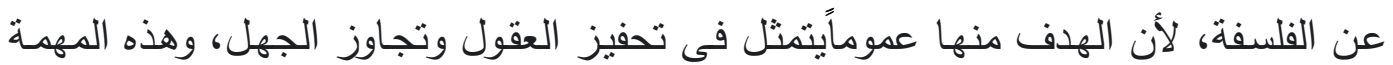

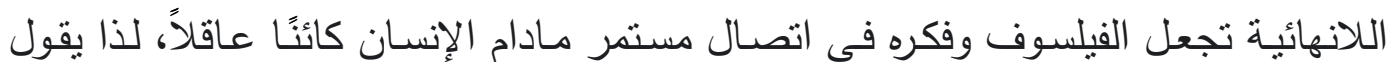
باسكال: " كل تهجم على الفلسفة هو تقلسف في حد ذاته ذاته". والعلوم التخصصية ذاتها، تثير نساؤلاتها الفلسفية التي قد تدخل في صميم استتناجانها

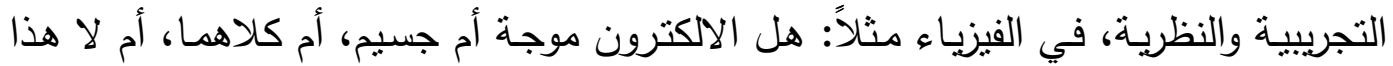

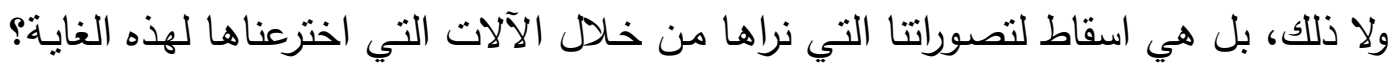

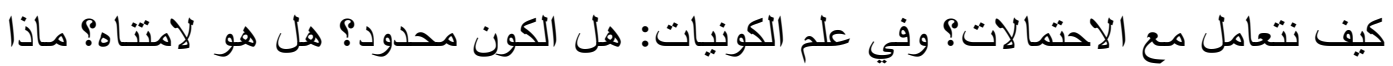

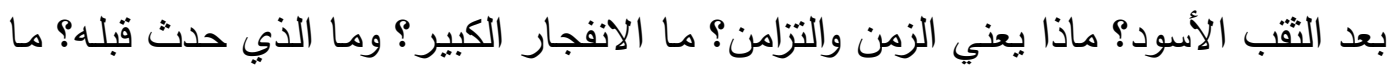

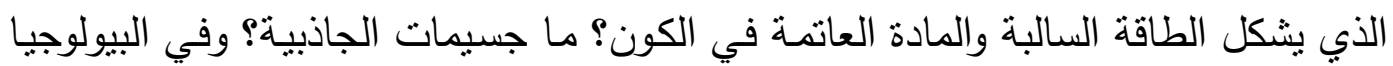

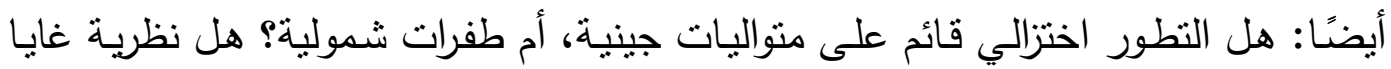

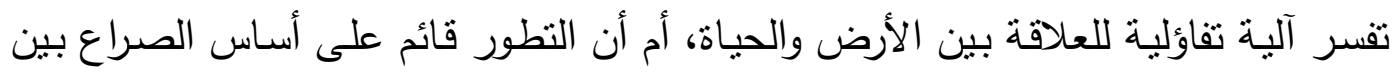

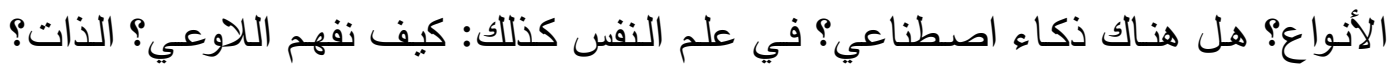

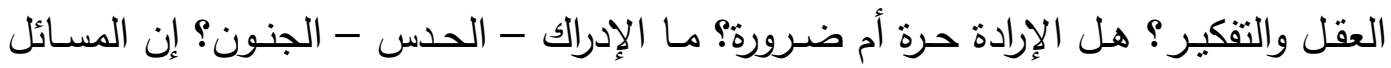

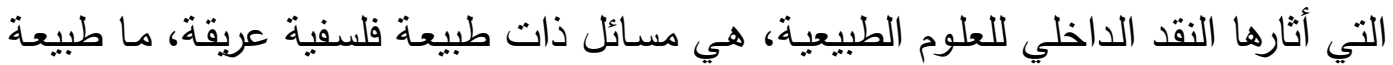

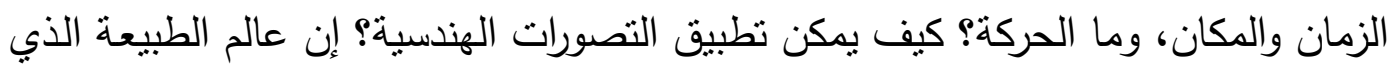

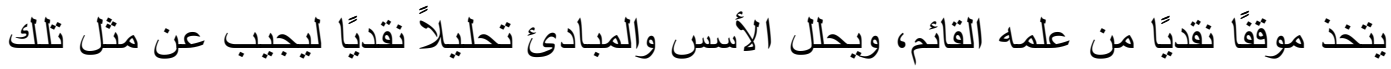

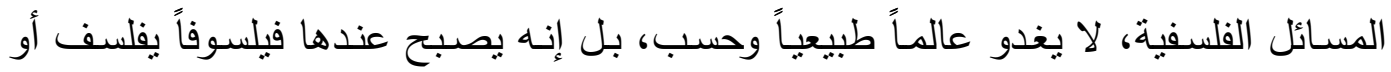

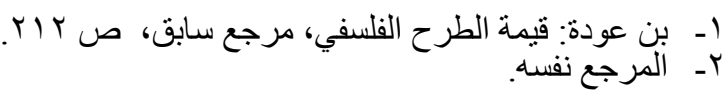


يُقوِّم علمه، كما يسهم معده الفيلسوف في مناقتشة وتحليل تللك المسائل الفلسفية العريقة في قدمها عند الفلاسفة (1).

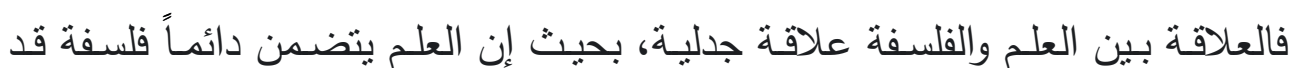

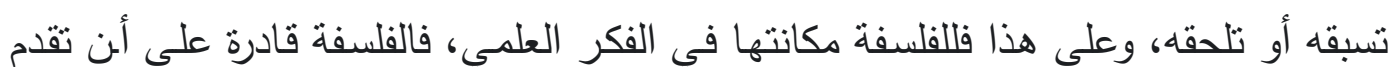

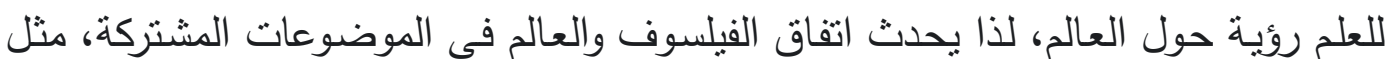

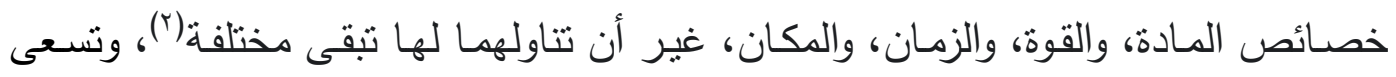

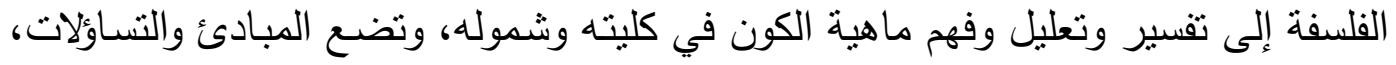

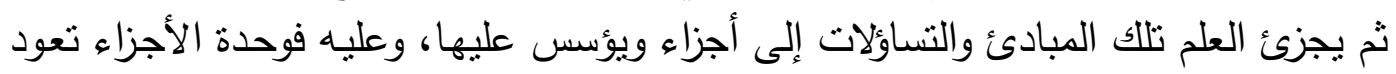

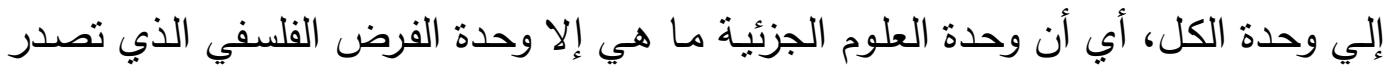

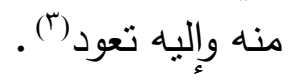

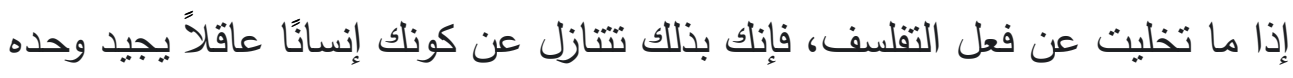

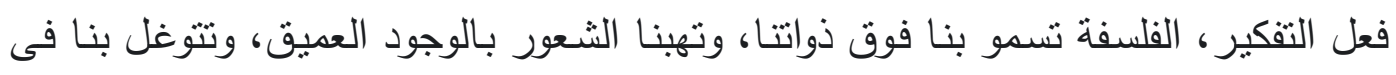

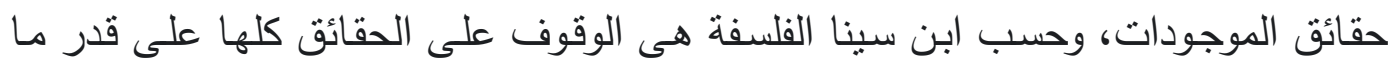

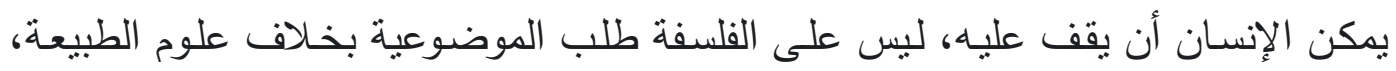

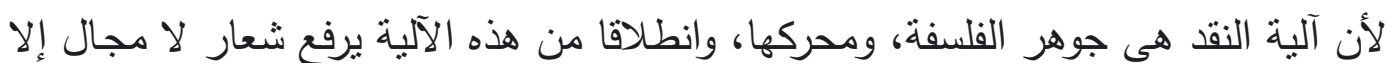

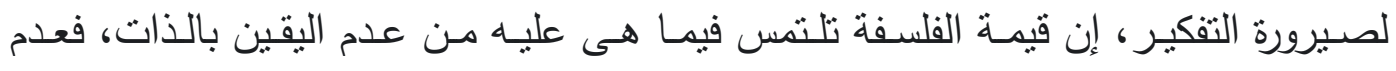

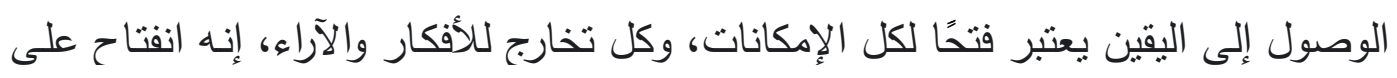

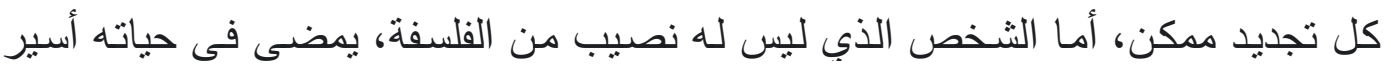

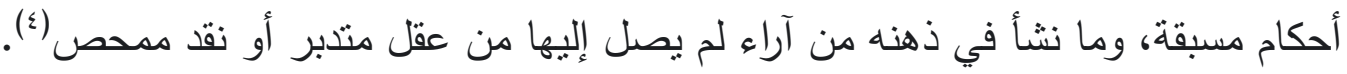

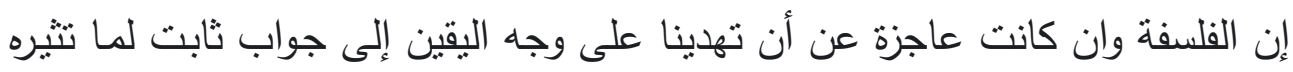

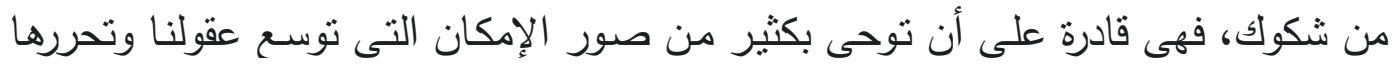

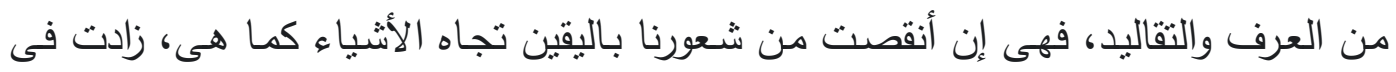

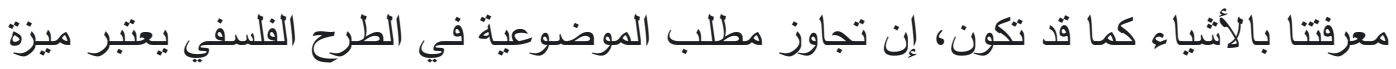
تتميز بها الفلسفة في مقابل العلوم الطبيعية وليس عيباً أبداً (ه).

1- www.maaber.org/issue_october17/epistemology1.htm.

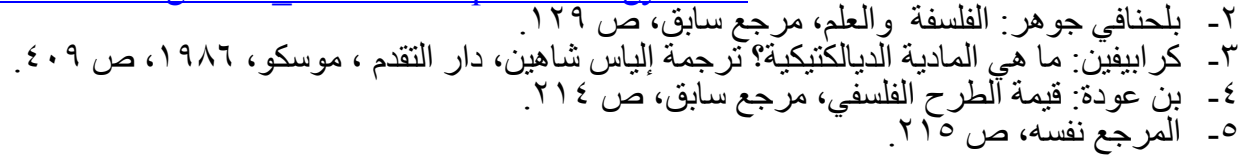

OVY 
لقد كان هناك إنتاج فائض من الفروض الفلسفية على الحدود البعيدة للمعرفة العلمية،

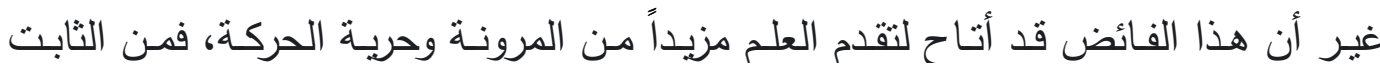
تاريخياً أن حصاداً كبيراً من الأفكار التي أسهمت في هذا التقدم العلمي قد جُنى من بين كثير من المناقشات الفلسفية.

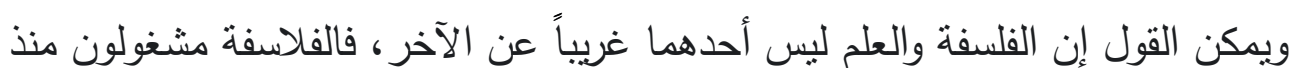

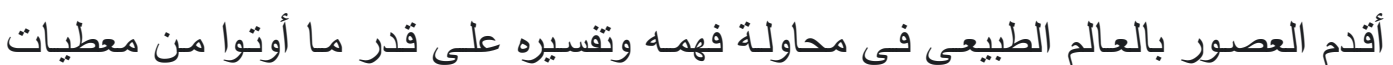

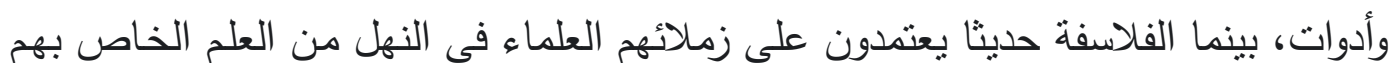

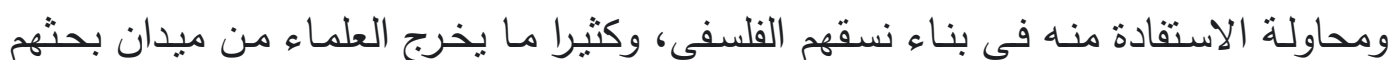

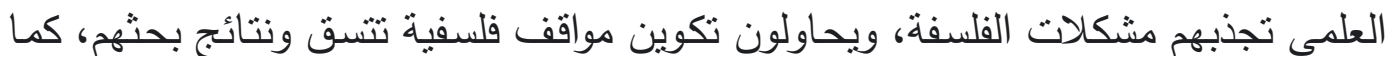
ينهلون من تراث الفلاسفة، وبذلك يهتم الفلاسفة بأبحاث العلماء كما يهنت العلمـاء باتخاذ مواقف فلسفية تتسق ونتائج بحنثه ('). فالعلم، كمنتج إنساني هو استجابة عن حالة اغتراب كائن برى نفسه وحيداً في اتساع

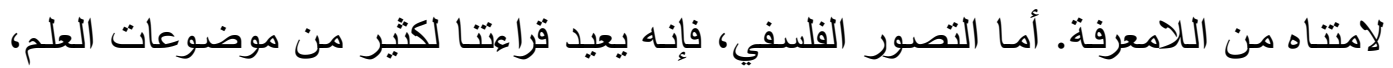

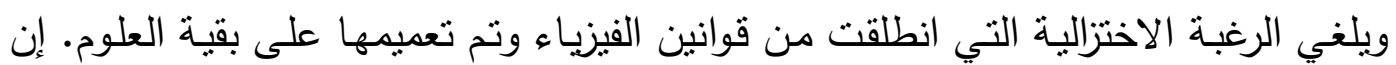

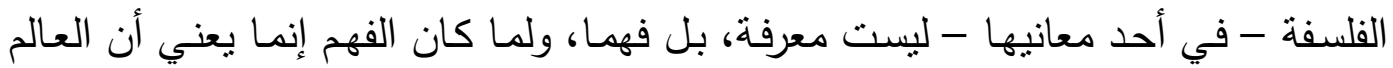
يقبل التعقل، فإن مبدأ السبب الكافي هو الفرض الضروري الذي تقوم عليه كل فلسفة، وعبثاً يحاول البعض أن يرفع عن الفلسفة صبغتها العقلية، إذ لا يمكن أن تقوم فلسفة ضدي العب العقل، كما لا يوجد فن ضد الجدمال.

وتستهدف الأنسقة العلمية، من الناحية الفلسفية دعم الانتظام التفسيري والتتبؤي ضمن معطيات الخبرة الغاية في التعقيد، أي الظواهر التي يمكن ملاحظتها مباشرة من قِبلنا، لذا لذانها

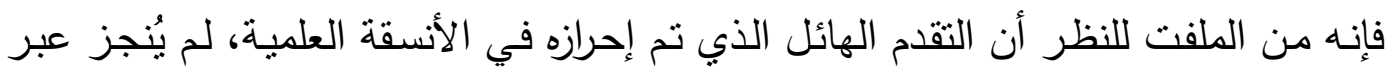

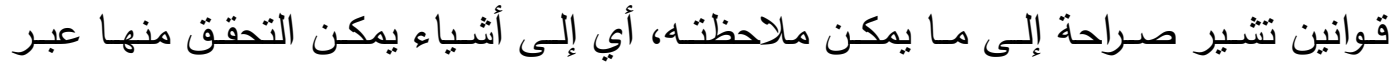
الملاحظة المباشرة، بل عبر قوانين تتحدث عن مختلف الكينونات الفرضية أو النظرية، أي إي أثنياء وحوادث وخصائص مفترضة لا يمكن لنا إدراكها أو ملاحظتها بطربقة مباشرة، أو بأي

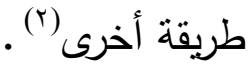

2- http://www.maaber.org/issue_october17/epistemology1.htm. 


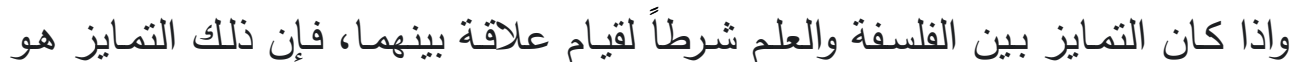

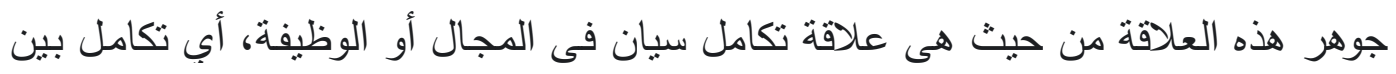

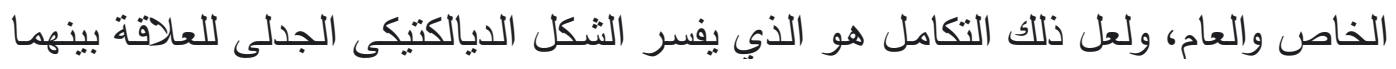

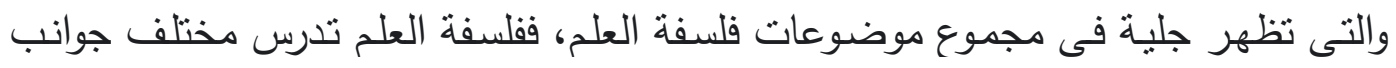

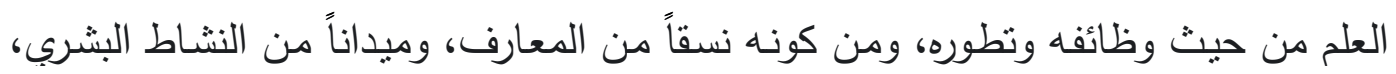

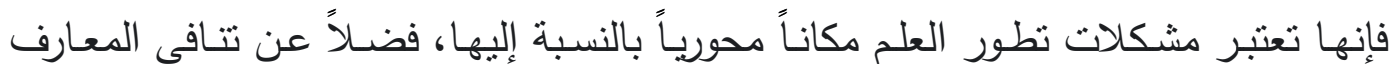

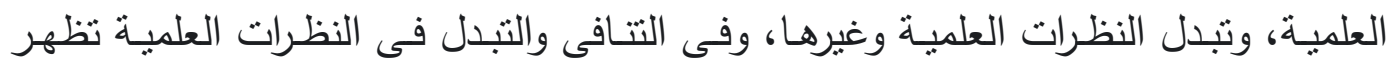

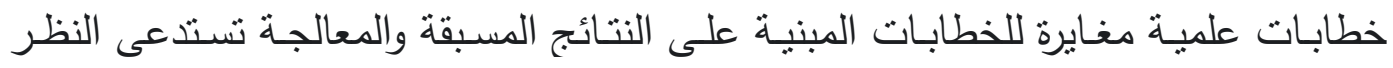

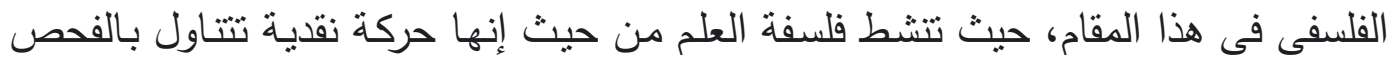

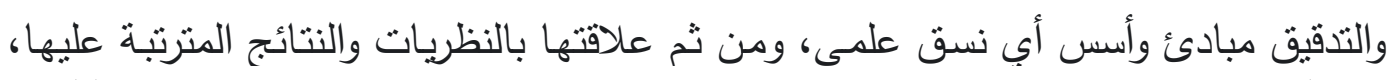
فضلاً عن فحص وتحليل بعض المفاهيم التي يستتد إليها العلماء في دعم استخلالاتهم (').

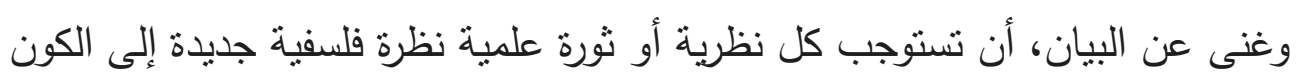

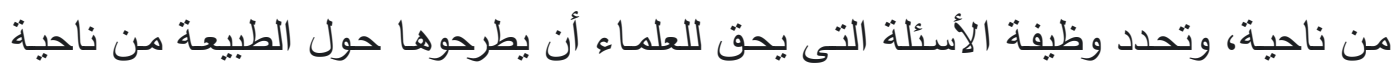

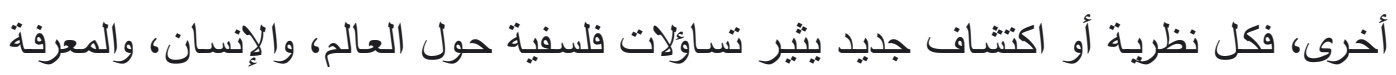

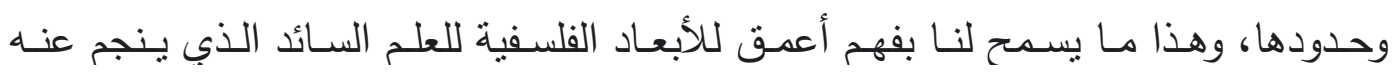

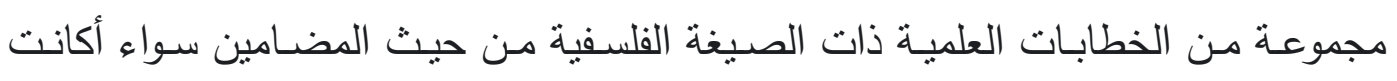

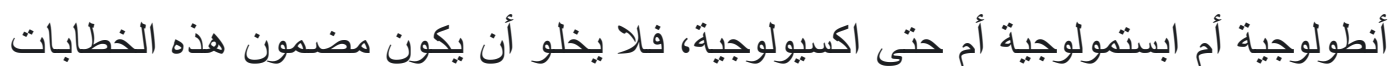

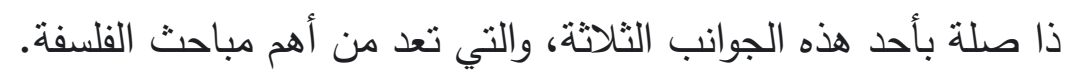

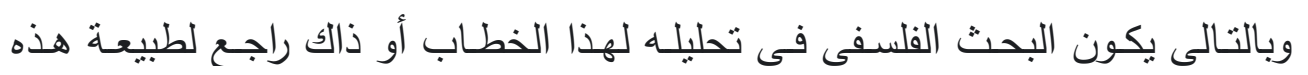

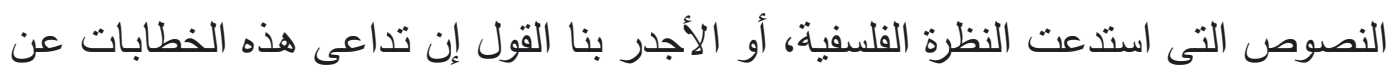

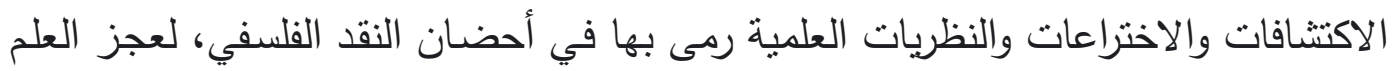

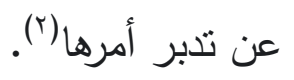

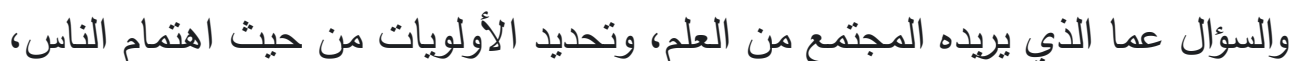

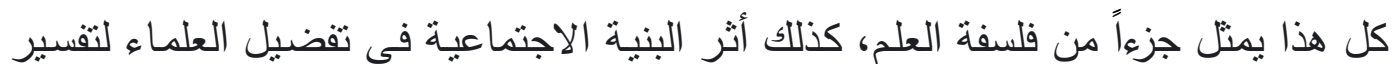

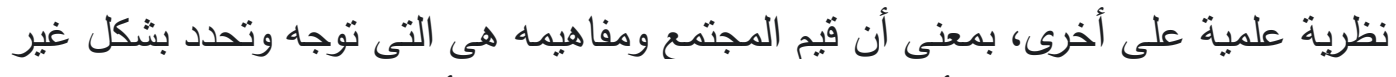

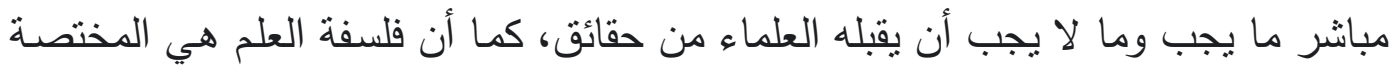

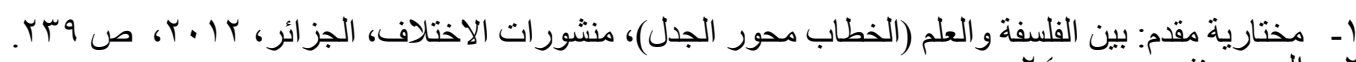

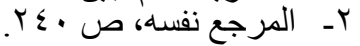


بالتقويم الأخلاقى للـدور الذي يقوم بـهـ العـالم، ومدى مسئوليته عن الاستخدام السياسـي

والاستراتيجي للنظريات العلمية (1)

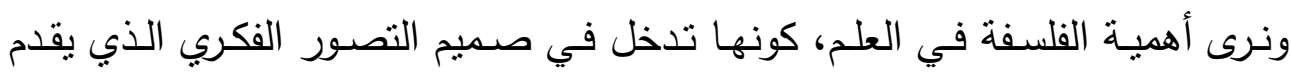

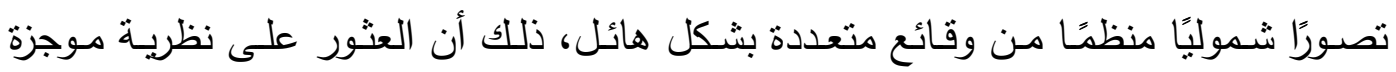

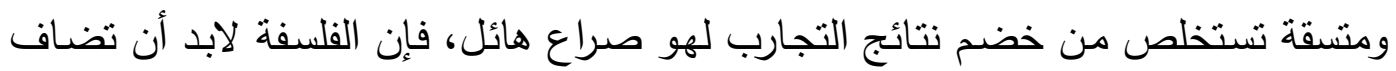

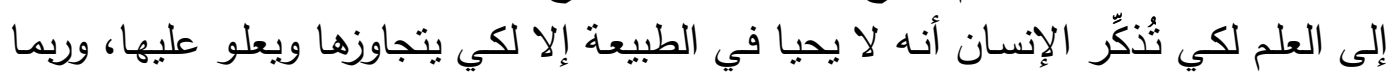

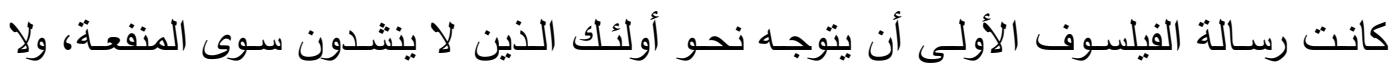
يهتمون إلا بالنتائج العملية.

ومن خصائص روح التفكير العلمي الني يشترك فيها مع الفلسفة، هي خاصية البحث

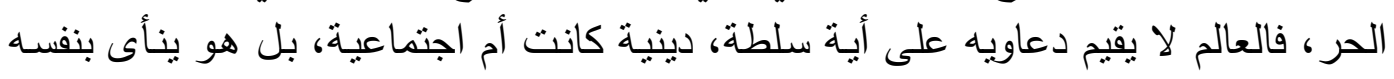

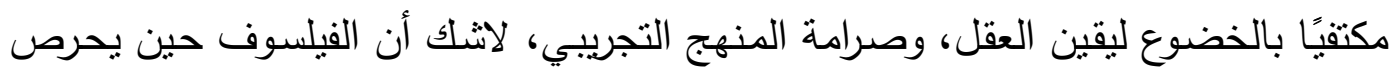

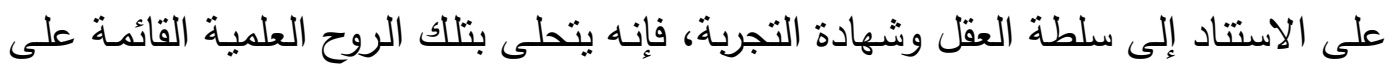

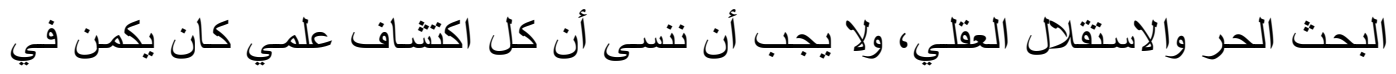

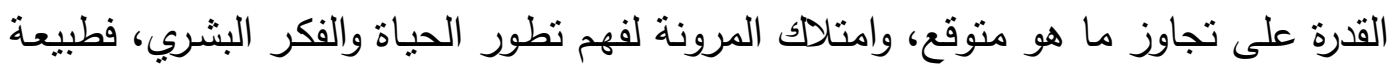

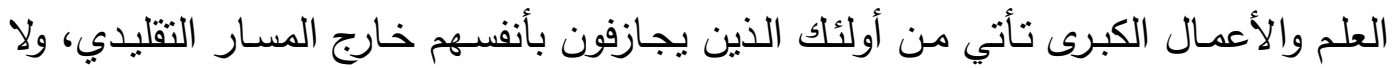

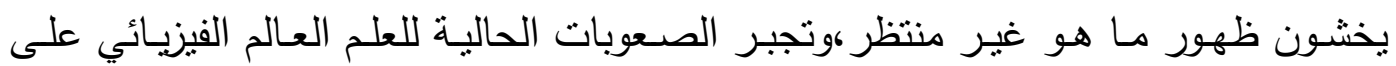

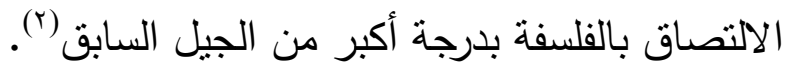

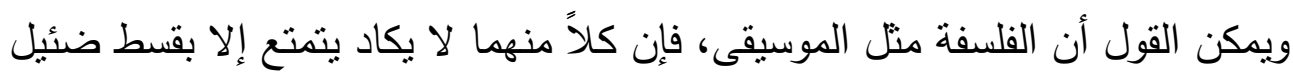

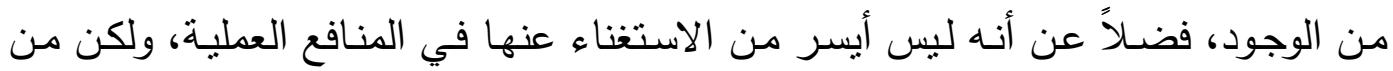

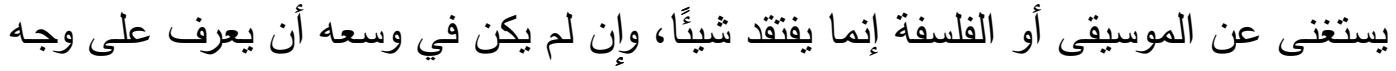
التحديد ما الثيء الذي يفتقده.

\section{أهمية فلسفة العلم للعلوم المختلفة:}

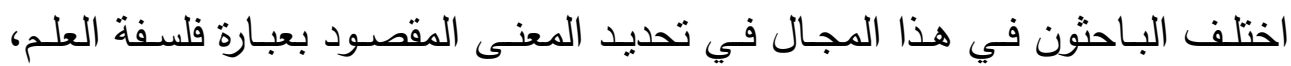

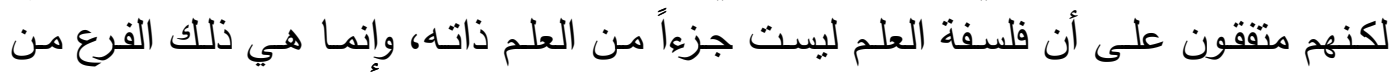

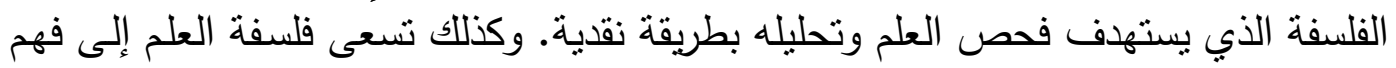

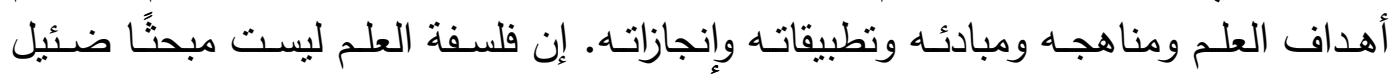

2- http://www.maaber.org/issue october17/epistemology1.htm. 
الثأن، بل إن فلسفة العلم كثيرا ما تمس مجالات مهمة في العلم. فعلى سبيل المثال، نجد

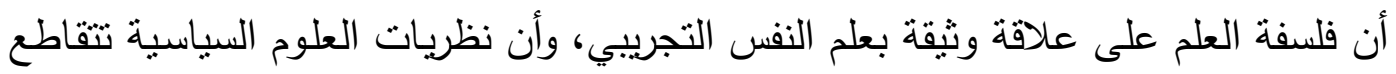

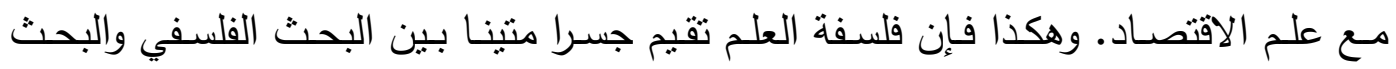

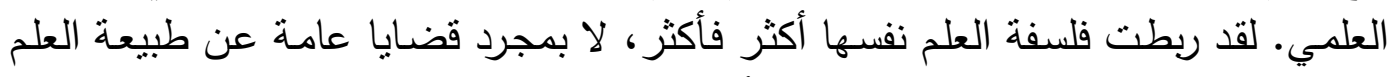

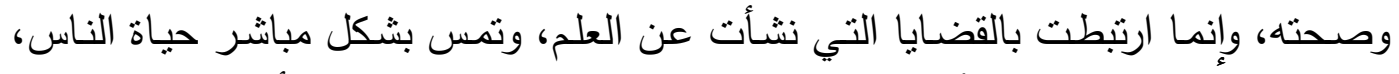

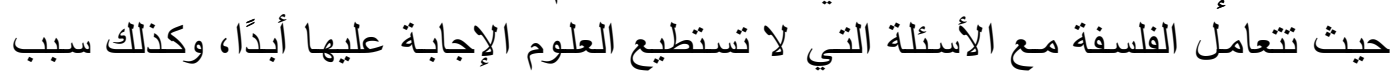

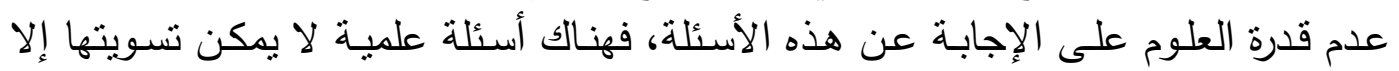

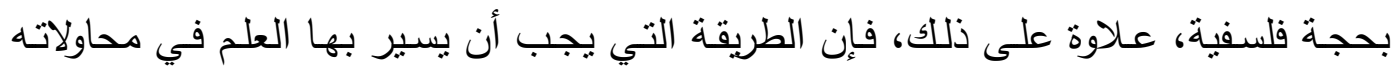

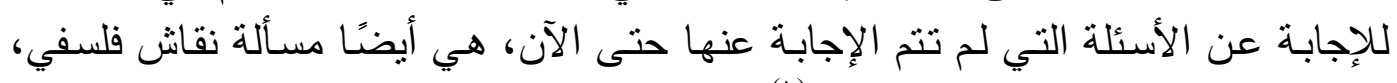

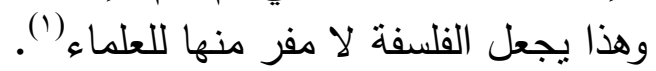

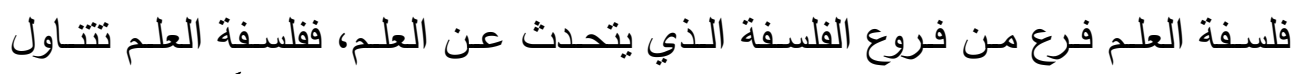

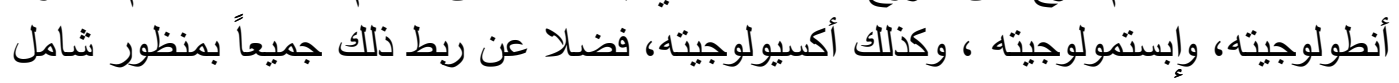

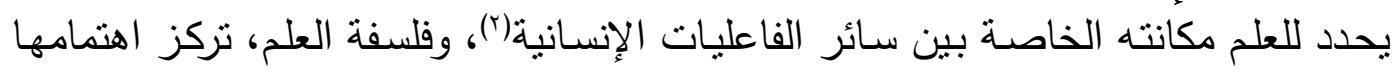

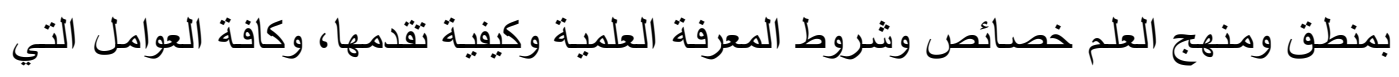

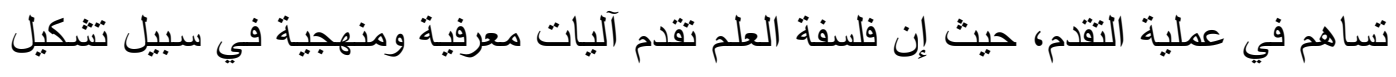
العقل، لتمكينه من حل كافة المشـاكل التي تعترضـه، ثم إزالة العقبات التي تعرقل المسيرة

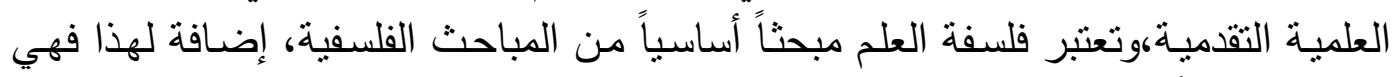
الأصدق تعبيراً عن روح عصر العلم الذي تضاعفت فيه المعارف العلمية بشكل كبير ، فهي تقدم رؤية نقدية وتصويبية تهدف في مجملها إلى نتكيل طوق نجاة في مرحلة بناء عقلية علمية منشودة.

كما أن فلسفة العلم المعاصرلا تهتم فقط بالعلم كما يجب أن يكون، بل إنها تهتم بالعلم

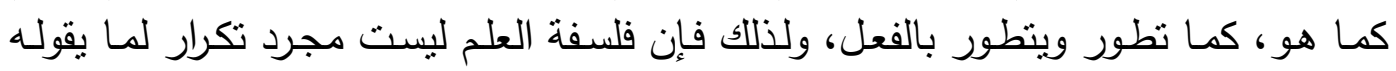

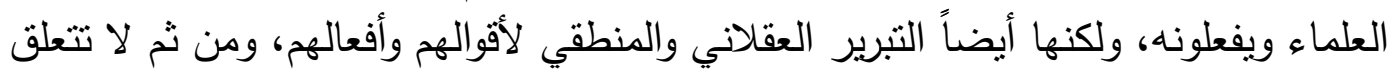

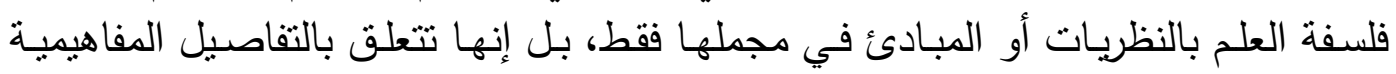

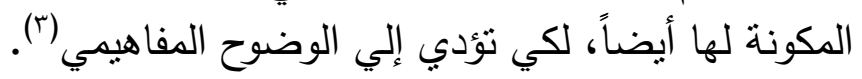

1- Alex Rosenberg: Philosophy of Science A Contemporary Introduction, Rutledge, New York, 2005, p 2.

r.

3- Hanson N.R: The Irrelevance of History of Science to Philosophy of Science, in: What I Do not Believe and Other Essays,eds, by Stephen Toulmin and Harry Woolf, Redial publishing company, Dordrecht, Holland, 1971, P281. 
العلاقة بين العلم والفلسفة ليست علاقة خصومة كما يعتقد البعض، فالخصومة أبعد

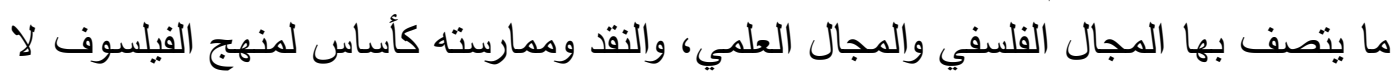

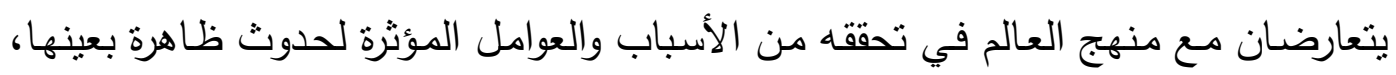

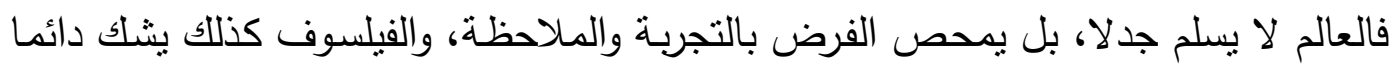

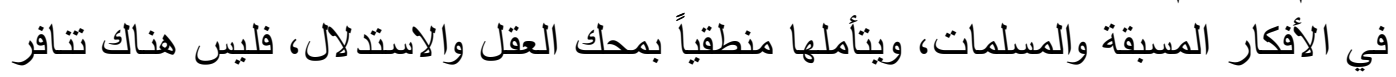

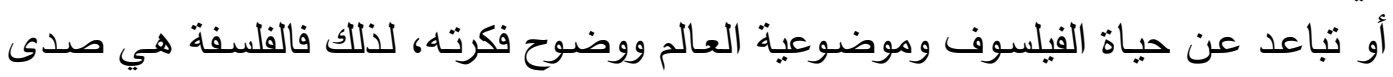

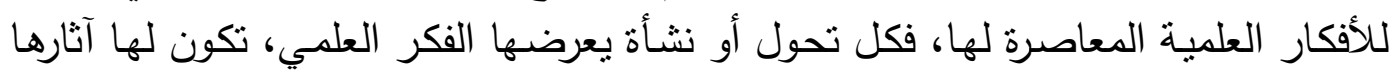

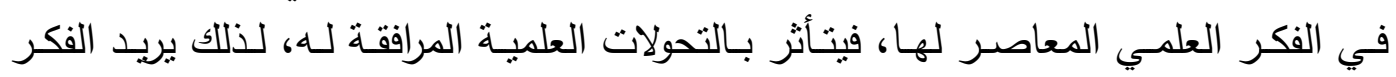

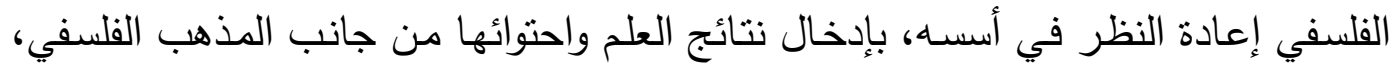

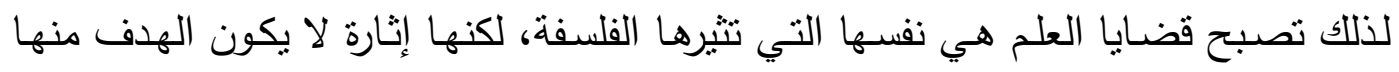

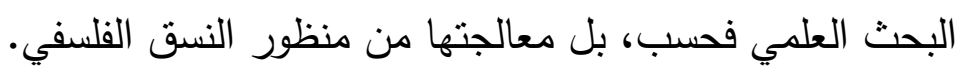


1- أثثر محسن الهاثمي: آلية الدفارقة (تعريفها، أنواعها، طريقة بنائها)، مجلة ثقافتتا،

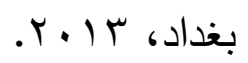

r- أندريه لالاند: موسوعة لالاند الفلسفية، منشورات عويدات، بيروت- باريس، طا،

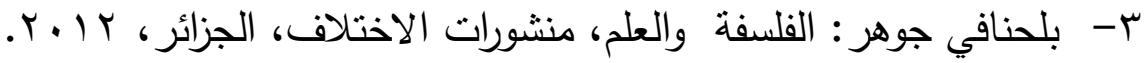

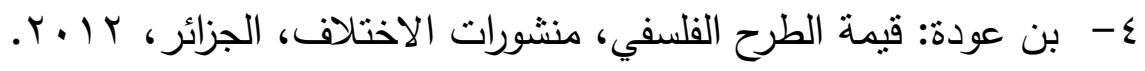

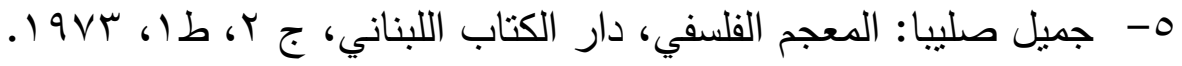

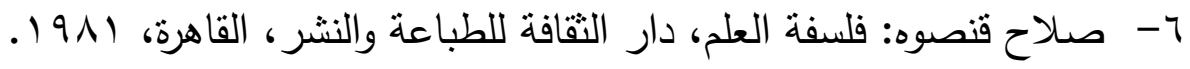

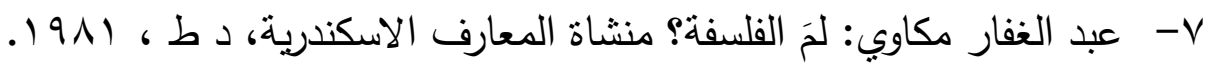

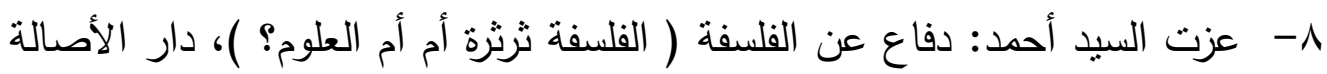

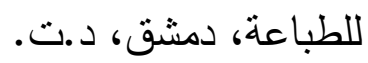

9- علي أحمد الصباحي: مفهوم وحدة العلوم في فلسفة كل من أوتونويراث وكارناب،

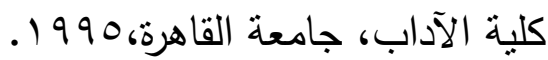

• 1-كرابيفين: ما هي المادية الديالكتيكية، ترجمة إلياس شاهين، دار التهار التقدم، موسكو،

$$
.1914
$$

11-محمد عبد الرحمن مرحبا، المسألة الفلسفية، منشورات عويدات،بيروت، لبنان،

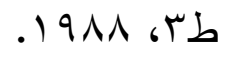

r ا-مختاريه مقدم: بين الفلسفة والعلم ( الخطاب محور الجدل)، منشورات الاختلاف،

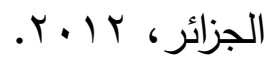

r ا-نايف بلوز : مناهج البحث في العلوم الطبيعية، مطبعة الإنشاء، دمشق، 910 (1)

14-Alex Rosenberg: Philosophy of Science a Contemporary Introduction, Rutledge, New York, 2005.

15-Hanson N.R: The Irrelevance of History of Science to Philosophy of Science, in: What I do not Believe and Other Essays, eds, by Stephen Toulmin and Harry Woolf, Redial publishing company, Dordrecht, Holland, 1971. 
1- filosofia-nabilmeciad.eklablog.com/-c2953223.

2- http://elearning.univannaba.dz $/ \mathrm{mod} /$ page $/$ view. php?id=3800.

3- http://www.maaber.org/issue_october17/epistemology1.htm

4- https://elaphmorocco.com/Web/opinion/2018/03/20502.ht m. 
○人。 